\title{
Grain Refining by Ultrasonic Stirring of the Weld Pool
}

\author{
Tao Yuan ${ }^{\mathrm{a}}$, Sindo Kou ${ }^{\mathrm{b},}$ and Zhen Luo ${ }^{\mathrm{a}}$ \\ ${ }^{\mathrm{a}}$ School of Materials Science and Engineering, Tianjin University, Tianjin 300072, \\ China \\ ${ }^{\mathrm{b}}$ Department of Materials Science and Engineering, University of Wisconsin, Madison, \\ WI 53706, USA
}

\begin{abstract}
Grain refining can improve the mechanical properties and solidification-cracking resistance of the weld. Ultrasonic grain refining was conducted by dipping an ultrasonic probe in the weld pool to stir it at a distance behind the arc. This new approach produced effective grain refining in arc welds of $\mathrm{Mg}$ alloys $\mathrm{AZ31} \mathrm{Mg}$ and AZ91 Mg. Grain refining increased when the probe was positioned farther behind the arc. This suggests the initial crystallites or dendrite fragments generated by ultrasound in a cooler melt farther behind the arc were better able to survive. This also suggests dendrite fragmentation was more likely to occur because the probe was closer to the mushy zone. However, a probe too far behind the arc ended up being inside the mushy zone and grain refining, though highly effective, was restricted to only near the weld centerline. At the same probe position, grain refining increased with increasing ultrasound amplitude. Grains were significantly finer in AZ91 Mg welds than AZ31 $\mathrm{Mg}$ welds. This suggests grain refining increased with increasing constitutional supercooling caused by the higher solute content of AZ91 Mg than AZ31 Mg.
\end{abstract}

\footnotetext{
*Corresponding author.
} 


\section{Introduction}

Grain refining of welds has been an active area of research in welding because finer grains can improve the strength, ductility and toughness of the weld and increase its resistance to cracking during solidification [1]. Numerous techniques for grain refining in welding have been studied, such as arc pulsation $[2,3]$, arc oscillation $[3$, 4], inoculation [5-7], electromagnetic weld-pool stirring [8, 9], and ultrasonic weld-pool vibration [10-13]. The approach of using advanced welding power sources for grain refining is attractive because it requires no additional devices to oscillate the arc or stir the pool, nor preparation of special filler metal containing inoculants. For example, in gas-tungsten arc welding He et al. [10] excited the arc by using high frequency current to generate ultrasonic waves, which caused weld pool vibration and grain refining in welding Ti-4Al-4V alloy. For another example, using an advanced gas-tungsten arc welding power source that allowed special AC pulsing, Babu and Cross [2] grain refined AZ31 Mg welds. Naturally, advanced welding power sources cannot be expected to work in all situations. For instance, the filler metal can interfere with the arc that is set up to generate ultrasonic waves or fine-tuned to pulse with special current and voltage waveforms. Thus, other approaches to grain refining in welding do have merits. An example is ultrasonic weld pool vibration by mechanical means.

Effective grain refining was achieved by ultrasonic vibration of the workpiece in gas-tungsten arc welding of $7075 \mathrm{Al}$ alloy [11] and in shielded-metal arc welding of 316L stainless steel [12]. The ultrasonic machine in the former was $2 \mathrm{~kW}$ in power 
and $20 \mathrm{kHz}$ in frequency. It was not specified in the latter, but the use of a $1.5 \mathrm{~kW}, 20$ $\mathrm{kHz}$ machine was reported in a related study by the same group [13].

The ultrasonic intensity can be defined as $I=\rho c(2 \pi f A)^{2} / 2(\rho$ is the liquid density, $c$ speed of sound in the liquid, $f$ ultrasound frequency and $A$ ultrasound amplitude), and fully developed cavitation can occur in liquid $\mathrm{Mg}$ when $I \geq 80 \mathrm{~W} / \mathrm{cm}^{2}$ [14]. With a very small probe for ultrasonic stirring in a very small volume of liquid in a gas-tungsten arc weld pool, melt wave resistance can be expected to be minimal and a smaller and hence less expensive ultrasonic machine may suffice.

Unfortunately, when the workpiece is clamped down tightly to a rigid fixture or connected to a rigid structure, ultrasonic vibration of the workpiece can be difficult. An alternative to overcome this problem was to attach a filler-wire guide to the sonotrode and put the filler wire tip in contact with weld pool edge to transmit ultrasonic waves to the weld pool [15]. The ultrasonic power source was $600 \mathrm{~W}$ and $19 \mathrm{kHz}$. The use of this smaller ultrasonic machine was possible because the wire guide and the weld pool were both very small. This can be another advantage of this approach. Unfortunately, due to its low melting point, the filler wire tip had a tendency to melt, ball up and stop grain refining when moved closer to the arc to improve weld pool vibration.

The purpose of the present study was to explore a new approach in which an ultrasonic probe is dipped directly in the weld pool of a Mg alloy and determine how the following factors affect grain refining: 1. the ultrasound amplitude, 2. the distance between the probe and the arc, and 3. the alloy composition. 


\section{Experimental Procedure}

The experimental approach was to dip an ultrasonic probe, smaller in diameter and much higher in melting point than a filler wire, directly in the weld pool to stir it at a distance behind the arc. This new approach allowed the workpiece to be clamped down tightly as required to avoid distortion induced by welding. It also allowed the probe position in the weld pool to be changed as needed.

The ultrasonic probe was a tungsten rod of $0.5 \mathrm{~mm}$ diameter (melting point 3407 $\left.{ }^{\circ} \mathrm{C}\right)$. The fine tungsten rod minimized heat extraction from the weld pool. Except for a short section near the weld pool, the rod was inside a 304 stainless steel tube $(0.82$

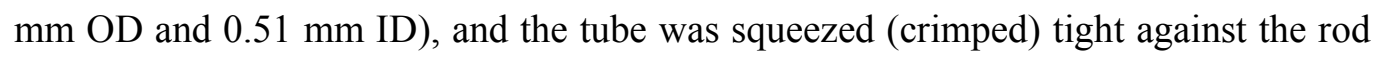
to stiffen it. The stainless steel tube was mounted on the sonotrode of a STAPLA ultrasonic welding machine, which was available to the authors. The machine was 3 $\mathrm{kW}, 20 \mathrm{kHz}$, and the amplitude was adjustable from $14 \mu \mathrm{m}$ at step one to $28 \mu \mathrm{m}$ at step ten. The probe vibrated in a horizontal plane in the direction normal to the welding direction.

Figure 1 shows schematically the ultrasonic grain refining process used in the present study. For convenience of subsequent discussion, three possible mechanisms of grain refining are also included. The tip of the ultrasonic probe was dipped in the weld pool from below as illustrated in Fig. 1a. The distance between the probe and the axis of the electrode is called the offset. The workpiece was mounted on a motor-driven carriage that travels in the direction indicated by the arrowhead. The electrode, pool and probe do not travel. 
The welding torch was mounted on an $\mathrm{x}-\mathrm{y}$ sliding stage driven by precision lead screws that advanced the stage $1 \mathrm{~mm}$ per revolution (360 degrees) in either direction. This allowed the horizontal distance between the electrode axis and the probe to be set with a precision much better than $0.1 \mathrm{~mm}$. At the end of welding the arc was turned off abruptly to help preserve the steady-steady pool shape. The travel of the workpiece was stopped simultaneously. The distance between the probe and the weld pool boundary in the welding direction was measured after welding. The sensitivity of controlling the location of the probe from the pool boundary along the welding direction is estimated to be about $\pm 0.2 \mathrm{~mm}$.

In order to investigate the effect of the offset over a wide range, the probe was positioned from 0 to $8 \mathrm{~mm}$ behind the electrode axis. After a steady weld pool was established, the sonotrode was raised to dip the probe tip in the weld pool. It is believed that dipping an ultrasonic probe into the weld pool from above, at a short distance behind the arc, is also feasible since the probe is very small. A small water-cooled $\mathrm{Cu}$ holder with Ar shielding can be used to protect the probe from the arc.

Two commercial Mg alloys were selected for welding, i.e., wrought alloy AZ31 $\mathrm{Mg}$ (nominal composition $\mathrm{Mg}-3.0 \mathrm{Al}-1.0 \mathrm{Zn}-0.6 \mathrm{Mn}$ ) and casting alloy $\mathrm{AZ91} \mathrm{Mg}$ (nominal composition Mg-9.0Al-0.7Zn-0.2Mn). The workpiece was $102 \mathrm{~mm}$ long, $102 \mathrm{~mm}$ wide and $1.6 \mathrm{~mm}$ thick. It was bead-on-plate welded without a filler metal by gas-tungsten arc welding along the centerline of the workpiece top surface. The welding direction was normal to the rolling direction in the case of AZ31 Mg. The 
welding conditions were as follows: direct current electrode negative, 2\%-thoriated tungsten electrode $3.2 \mathrm{~mm}$ in diameter with a $50^{\circ}$ included angle, $1.5 \mathrm{~mm}$ arc gap, and pure Ar shielding at $1 \mathrm{~m}^{3} / \mathrm{h}(16.5 \mathrm{~L} / \mathrm{min})$.

Table 1 summarizes the conditions used for welding and ultrasonic stirring. After welding, the tip of the tungsten probe was easily separated from the weld. No bonding or reaction with $\mathrm{Mg}$ was noticed. The resultant welds were cut and their top surfaces polished and etched to reveal the grain structure. The grain structure at the bottom surfaces was also checked, and it was similar to that at the top surfaces. A shallow track was left by the probe at the weld bottom surface, visible with AZ31 Mg but not AZ91 Mg.

AZ31 Mg welds were etched with a solution consisting of $3 \mathrm{ml} \mathrm{HCl}$ and $100 \mathrm{ml}$ anhydrous ethyl alcohol. This revealed the dendritic structure but not the grain structure. A different etching solution was used, containing $10 \mathrm{ml}$ glacial acetic acid, $10 \mathrm{ml}$ distilled water, $6 \mathrm{~g}$ picric acid and $100 \mathrm{ml}$ anhydrous ethyl alcohol, and micrographs were taken with polarized light to show different grains in different colors.

No electron back scatter diffraction (EBSD) images were provided to further confirm that the optical micrographs showing grain refining are clear proof of dendrite fragmentation due to ultrasonics instead of due to sectioning effects. However, it should be pointed out that optical micrographs have always been the standard way of studying grain refining and its mechanisms, both in welding and 
casting. In fact, optical micrographs were used throughout the many studies cited in the present study, including those on ultrasonic grain refining.

As for AZ91 Mg a simple procedure is known to bring out its grain structure very clearly, more effective than polarized light. The commonly used T4 heat treating procedure followed by quenching was used to dissolve the $\mathrm{Mg}_{17} \mathrm{Al}_{12}$ phase along grain boundaries (and within grains). This procedure, which allows no grain growth, brings out grain boundaries clearly $[16,17]$. The heat treated specimens were then polished and etched with a solution of $20 \mathrm{ml}$ glacial acetic acid, $10 \mathrm{ml}$ distilled water, and $100 \mathrm{ml}$ anhydrous ethyl alcohol. Grain size measurements were carried out according to ASTM Standard E112 [18] at different locations within the region of grain refining, where the average grain size is called the refined grain size or simply the grain size. The area fraction of refined grains was calculated by dividing the area of refined grains by that across the entire weld.

The microstructure of the welds was also examined by scanning electron microscopy (SEM), with energy dispersive X-ray spectroscopy (EDS) to analyze the compositions of the intermetallic and matrix phases.

\section{Results and discussion}

As mentioned previously, for convenience of discussion three mechanisms of grain refining in welds are illustrated in Fig. 1c, including heterogeneous nucleation, dendrite fragmentation and grain detachment. These mechanisms in aluminum arc welding were discussed by Kou and Le [19]. Heterogeneous nucleation and dendrite fragmentation are well known grain refining mechanisms in welding and casting. 
Grain detachment, however, may be less well known. Since the workpiece material around the weld pool is heated up to between the liquidus temperature $T_{L}$ and the eutectic temperature $T_{E}$, it is partially melted. If the partially melted grains carried away by fluid flow survive in the weld pool, they can grow into equiaxed grains to cause grain refining [1].

The results of ultrasonic grain refining are summarized in Table 1. EDS composition analysis showed no detectable tungsten in the weld. This indicates tungsten did not dissolve in the weld pool, consistent with visual inspections that showed no diameter reduction of the tungsten rod after weld pool stirring.

An example of the welds is shown in Fig. 2. The probe was pushed into the weld pool when the workpiece had travelled for about $15 \mathrm{~mm}$ after the arc was started. As shown, the weld reached a constant width after about $10 \mathrm{~mm}$ from its starting point, indicating that the steady-state welding condition had been reached.

Columnar grains were observed in welds made with the probe immersed in the weld pool but not oscillated during welding. An example is Weld \#1 shown in Fig. 3, which was etched with a solution consisting of $3 \mathrm{ml} \mathrm{HCl}$ and $100 \mathrm{ml}$ anhydrous ethyl alcohol. Fig. 3a shows the horizontal longitudinal micrograph of the weld, where the dark arrowhead indicates direction of workpiece travel while the white arrowheads indicate the fusion boundary. Long columnar dendrites are visible in the bulk fusion zone. They point inward from the fusion boundary and forward in the welding direction, typical of the columnar grain structure observed in welds made without grain refining. However, columnar dendrites are not visible in the transverse 
micrograph in Fig. 3b. This is because the transverse cross-section of a columnar dendrite may not necessarily look like one.

Figure $4 \mathrm{a}$ and $\mathrm{b}$ shows the same weld samples etched with a solution consisting of $20 \mathrm{ml}$ glacial acetic acid, $10 \mathrm{ml}$ distilled water and $100 \mathrm{ml}$ anhydrous ethyl alcohol. These micrographs were taken by polarized light to show the grain structure. The horizontal longitudinal cross-section in Fig. 4a shows columnar grains in the bulk fusion zone. In the transverse micrograph in Fig. $4 \mathrm{~b}$ columnar grains are clear near the fusion boundary, where they are more or less parallel to the transverse cross-section of the weld. In the bulk fusion zone, however, columnar grains are more or less normal to the transverse cross-section of the weld and thus do not look like columnar grains. Fig. 4c shows the transverse cross-section of a weld (Weld \#9) that was made under identical conditions as Weld \#1 (Fig. 4a, b) except the probe was oscillated at the amplitude of $26.44 \mathrm{~mm}$. As shown, the grains are equiaxed and much finer than those in Weld \#1 made with a still probe. The horizontal longitudinal cross-section of the weld also show fine equiaxed grains (as will be shown subsequently in Fig. 6b). Thus, grain refining by ultrasonic stirring of the weld pool is confirmed.

Optical micrographs of the AZ31 Mg welds are shown in Figs. 5 and 6. In order to explain these results, some mechanisms involved in ultrasonic stirring and grain refining in general $[14,20-27]$ need to be described briefly first. According to Abramov et al. [19], ultrasonic stirring in a liquid metal causes: (i) cavitation, and (ii) acoustic streaming. Cavitation involves the formation, growth, pulsation and collapse of tiny bubbles in the melt, the pressure impulse (compression) of which can be so 
high that the collapse of bubbles generates hydraulic shock waves. Acoustic streaming involves bulk fluid flow in the melt, which can vigorously mix the melt, homogenize its temperature, distribute nucleants in the melt, and enhance heat dissipation.

According to Ramirez et al. [25], ultrasonic grain refining can occur by: (i) cavitation-enhanced nucleation, and (ii) cavitation-induced (shock waves) dendrite fragmentation. Cavitation-enhanced nucleation can be further interpreted in terms of two different mechanisms: (i) cavitation-induced melting-point elevation, and (ii) cavitation-induced wetting. Cavitation-induced melting-point elevation can be explained by the Clausius-Clapyron equation, $\Delta T_{m}=T_{m} \Delta P \Delta V / \Delta H$, where $T_{m}$ is the melting point, $\Delta P$ pressure change, $\Delta V$ volume change upon melting, and $\Delta H$ heat of fusion [23, 24]. Based on the equation, Ramirez et al. [25] calculated a melting-point increase of $1.29-6.47 \mathrm{~K}$ for a $\mathrm{Mg}$ melt under a pressure pulse of $200-1000 \mathrm{~atm}$ caused by collapse of cavitation bubbles. The melting-point increase was considered sufficient to activate many of the particles in the melt near the collapsed bubbles. This is because an increase in the melting point is equivalent to increasing undercooling, leading to enhanced nucleation. Cavitation-induced wetting is explained as follows. Cavities and cracks on the surfaces of insoluble particles can be filled with the melt (that is, wetted by the melt) by the pressure pulse and the wetted particles thus act as effective nucleation sites, leading to enhanced nucleation. According to Liu et al. [26], a large number of solid impurity particles, such as the Mn-based intermetallic compounds, exist in the AZ91 melt. By cavitation-induced wetting a portion of these particles can become active nucleants and lead to nucleation upon a slight 
undercooling, consistent with cooling curves they measured during solidification. As for cavitation-induced (shock waves) dendrite fragmentation, Shu et al. [21] revealed by real-time imaging and analysis that the violent collapse of bubbles can create local shock waves to shatter dendrites nearby into small pieces in a few tens of milliseconds.

\subsection{Effect of ultrasound amplitude on grain structure}

Observation of the weld pool during welding indicated the pool was calm without any signs of turbulence. No signs of probe oscillation could be seen during welding. This is not surprising in view of the very small amplitude of oscillation used, that is, $26.44 \mu \mathrm{m}$ maximum. This amplitude is much smaller than the pool width, which is about $7 \mathrm{~mm}$ wide and $11 \mathrm{~mm}$ long. No significant difference in the pool shape or size caused by ultrasonic stirring was observed.

As shown by AZ31 Mg welds \#3 through \#7 in Table 1 and Fig. 5, under identical welding conditions and the probe offset, increasing ultrasound amplitude increases grain refining, including reducing the grain size and increasing the area fraction of refined grains. Weld \#7 is included for comparison here because its $6 \mathrm{~mm}$ offset is fairly close to the $5 \mathrm{~mm}$ offset of other welds. In each micrograph the fusion boundary (indicated by an arrow) is near the right side, and the weld centerline is near the left side.

In AZ31 Mg weld \#3 made at a low amplitude of $14 \mu \mathrm{m}$, some equiaxed grains are present along the weld centerline as shown in Fig. 5a. It is not clear if these equiaxed grains originated from initial crystallites due to cavitation-enhanced 
nucleation or dendrite fragments due to cavitation-induced dendrite fragmentation. In any case these initial crystallites or dendrite fragments were produced by ultrasonic stirring, and they were not carried far away from the probe probably because fluid flow induced by ultrasonic streaming was weak at low ultrasound amplitude. Consequently, grain refining is limited to near the weld centerline. However, with the amplitude increased to $23.33 \mu \mathrm{m}$ in weld \#6 and $26.44 \mu \mathrm{m}$ in weld \#7, more initial crystallites or dendrite fragments were generated by ultrasonic stirring. Since fluid flow induced by acoustic streaming was faster with higher amplitudes, they were carried farther across of the solidification front. Consequently, grain refining occurred in most of the weld as can be seen in Fig. $5 \mathrm{c}$ and d.

\subsection{Effect of probe position on grain structure}

In order to compare with AZ31 weld \#7, weld \#2 was made under identical conditions except the offset was changed from $6 \mathrm{~mm}$ to $0 \mathrm{~mm}$, that is, from $6 \mathrm{~mm}$ behind the arc to directly under it. Surprisingly, grain refining still occurred though limited. The grain size was $75 \mu \mathrm{m}$ instead of $52 \mu \mathrm{m}$ as in weld \#7, and the area fraction of refined grains was $26 \%$ instead of $87 \%$. Due to space limitation the micrograph is not shown here.

In order to study the effect of the offset on grain refining a series of welds was made. As shown by AZ31 Mg welds \#8 through 13 in Table 1 and Fig. 6, under identical welding conditions and ultrasound amplitude, grain refining increases with increasing offset, up to the solidification front. Farther behind the arc the melt is cooler and the initial crystallites generated by cavitation-enhanced nucleation can 
have a better chance to survive. Meanwhile, an ultrasonic probe farther behind the arc is closer to the mushy zone to cause cavitation-induced dendrite fragmentation. Since the melt is cooler here, and the dendrite fragments can have a better chance to survive.

As can be seen in Fig. 6c, with the $7 \mathrm{~mm}$ offset weld \#12 shows fine grains throughout the weld with an average grain size of $46 \mu \mathrm{m}$ (Table 1), which is close to that of $52 \mu \mathrm{m}$ obtained by Babu and Cross [2] in AZ31 Mg by AC pulsed gas-tungsten arc welding. This grain structure suggests the bulk fluid flow induced by acoustic streaming [20] appeared strong enough to carry the initial crystallites or dendrite fragments across the entire solidification front.

In arc welding fluid flow in the weld pool can be driven by gradients of the surface tension along the pool surface. The surface tension of liquid metal tends to decrease with increasing temperature, unless a significant amount of a surface-active agent (e.g., sulfur in steel and stainless steel) is present $[1,28]$. Thus, on the top surface the flow driven by surface-tension gradients is outward from near the arc, where the surface tension is lower due to the higher pool surface temperature, to the pool boundary, where the surface tension is higher due to the lowest pool surface temperature. So, initial crystallites or dendrite fragments near the pool surface may be carried away from the arc to survive near the pool boundary. Fluid flow in an arc weld pool can also be driven by the Lorentz force $[1,28]$. The force is inward and downward and so is the Lorentz-force-driven flow. This may cause the flow on the top surface to go in the opposite direction of that driven by surface-tension gradients. However, the Lorentz force may not be significant in a shallow weld pool under a 
small welding current of 60 A (weak-Lorentz force). During ultrasonic stirring of the weld pool, the bulk fluid flow induced by acoustic streaming, though the pattern of which is unknown, is likely to dominate over the flow induced either by surface-tension gradients or the Lorentz force.

As compared to weld \#12, the $95 \mu \mathrm{m}$ grain size in weld \#8 made without ultrasonic grain refining is much larger. Since the grain size is reduced by a factor of about 2 by ultrasonic grain refining, the grain density (i.e., number of grains per unit volume) is increased by a factor of about $2^{3}$ or 8 . Thus, by ultrasonic stirring of the weld pool, the total number of dendrite fragments and initial crystallites that grow into equiaxed grains increases by a factor of about 8 .

A highly non-uniform weld grain structure was observed when the offset was further increased. AZ31 Mg weld \#13 in Fig. 6d was made with the probe moved further from 7 to $8 \mathrm{~mm}$ behind the arc. A band of very fine grains of average grain size $31 \mu \mathrm{m}$ exists along the weld centerline (near the left side of the micrograph), outside which coarse columnar grains still exist. This grain structure suggests the ultrasonic probe was inside the mushy zone. Examination of the position of the weld crater relative to the positions of the probe and the electrode indicated the pool boundary, that is, the solidification front, at the weld centerline was about 7.0 to 7.5 $\mathrm{mm}$ behind the electrode axis during welding. Since the offset was $8 \mathrm{~mm}$, the probe was about 0.5 to $1.0 \mathrm{~mm}$ behind the solidification front. Thus, the probe was inside the mushy zone during welding. When surrounded by dendrites, the ultrasonic probe can easily break off their tips into very fine pieces as observed by Shu et al. [21]. 
Consequently, very fine grains form near the weld centerline. However, since dendrite fragments are inside the mushy zone, they are less likely to be carried by bulk fluid flow to elsewhere along the solidification front to form fine equiaxed grains away from the weld centerline.

Figure 7 summarizes the effect of ultrasonic weld pool stirring on grain refining in the AZ31 Mg welds. There is not much grain refining if the offset of the probe and the amplitude of oscillation are both small as illustrated in Fig. 7a. On the other hand, extensive grain refining is possible if the offset and the amplitude are both high. With further increase in the offset, however, the probe can end up being inside the mushy zone. The amplitude of oscillation can be significantly reduced by the much higher resistance of the mushy zone to probe oscillation. Furthermore, the dendrite fragments inside the mushy zone cannot be carried by bulk fluid flow to elsewhere along the solidification front. Thus, grain refining, though highly effective, is limited to near the centerline of the weld.

The equiaxed grains in weld \#12 are shown in Fig. 7d. Particles and needles are embedded in the Mg-rich primary solidification phase (Mg). EDS analysis showed the particles contained $\mathrm{Al}$ but no $\mathrm{Mn}$, thus suggesting they are the $\gamma\left(\mathrm{Mg}_{17} \mathrm{Al}_{12}\right)$ phase. They are likely the divorced eutectic that forms with the eutectic part of the (Mg) phase connected to the primary solidification phase $(\mathrm{Mg})$. On the other hand, the needles contained both $\mathrm{Al}$ and $\mathrm{Mn}$, thus suggesting they can be an intermetallic compound $\mathrm{Al}_{\mathrm{x}} \mathrm{Mn}_{\mathrm{y}}$ such as $\mathrm{Al}_{8} \mathrm{Mn}_{5}, \mathrm{Al}_{11} \mathrm{Mn}_{4}$ or $\mathrm{Al}_{4} \mathrm{Mn}$. There is no clear evidence to prove that heterogeneous nucleation occurred from an $\mathrm{Al}_{\mathrm{x}} \mathrm{Mn}_{\mathrm{y}}$ intermetallic 
compound. The columnar and equiaxed grains in weld \#13 are shown in Fig. 7e and 7f, respectively. These equiaxed grains are significantly finer than those in weld \#12 (Fig. 7d).

The formation of $\mathrm{Al}_{\mathrm{x}} \mathrm{Mn}_{\mathrm{y}}$ intermetallic compounds during the solidification of AZ31 $\mathrm{Mg}$ is shown in Fig. 8. For the purpose of comparison, AZ91 $\mathrm{Mg}$ is also included. These curves of temperature $T$ vs. fraction solid $f_{S}$ were calculated using the thermodynamic software Pandat [29] and $\mathrm{Mg}$ database PanMagnesium [30] of CompuTherm, LLC in Madison, WI. According to the curves, $\mathrm{Al}_{8} \mathrm{Mn}_{5}$ forms from the melt before the primary $\mathrm{Mg}$-rich phase $(\mathrm{Mg})$ does. In $\mathrm{AZ31} \mathrm{Mg}, \mathrm{Al}_{8} \mathrm{Mn}_{5}$ forms at $674^{\circ} \mathrm{C}$ and $(\mathrm{Mg})$ at $632^{\circ} \mathrm{C}$. In the case of $\mathrm{AZ91} \mathrm{Mg}, \mathrm{Al}_{8} \mathrm{Mn}_{5}$ forms at $637^{\circ} \mathrm{C}$ and $(\mathrm{Mg})$ at $601^{\circ} \mathrm{C}$.

As mentioned previously, Liu et al. [26] suggested that by cavitation-induced wetting, some Mn-based intermetallic compounds in the AZ91 melt can become active nucleants. Since solid $\mathrm{Al}_{8} \mathrm{Mn}_{5}$ already exists in the melt before $(\mathrm{Mg})$ forms, it is possible for $(\mathrm{Mg})$ to nucleate on solid $\mathrm{Al}_{8} \mathrm{Mn}_{5}$ during cooling. However, there is no clear evidence can be seen in Fig. $7 d$ and $f$ that equiaxed grains nucleated from an $\mathrm{Al}_{\mathrm{x}} \mathrm{Mn}_{\mathrm{y}}$ intermetallic compound. In fact, the formation of very fine equiaxed grains along the centerline of weld \#13 suggests dendrite fragmentation is likely to be the dominating mechanism of grain refining. The effectiveness of a solid particle in the melt for heterogeneous nucleation is known to depend on the wetting angle of the particle by the melt and the surface roughness of the particle. Low wetting angles (i.e., better extents of wetting) are favored by a low-energy interface between the particle 
and the solid nucleus, which in turn is favored by a good lattice matching between the particle and the solid. Other factors can also affect the effectiveness, for instance, surface roughness and segregation, and chemical effects [31].

Detachment of partially melted grains may occur and help grain refining, as illustrated in Fig. 1c. This mechanism of grain refining can be more significant if the ultrasonic probe is positioned close to the leading portion of the pool boundary. With the probe positioned along the weld centerline, however, grain detachment is less likely to occur. When the offset is increased, the probe is farther away from the partially melted grains. Thus, grain detachment cannot explain why grain refining increases with increasing offset. In casting $\mathrm{Al}-2 \mathrm{Cu}$ with a $18-\mathrm{mm}$ diameter Mo-alloy sonotrode positioned at the center of the melt surface, Wang et al. [32] suggested that nucleated grains could also be generated by nucleation, growth and detachments of crystals form the radiating surface of the sonotrode if ultrasonic stirring continued for a period below the liquidus temperature. In the present study, however, the possibility of grain detachment from the sonotrode seems low in view of the very small heat sink provided by the $0.5 \mathrm{~mm}$-diameter sonotrode.

In principle, the temperature distribution in the weld pool can be calculated with the probe dipped in the weld pool and this may indicate whether the liquid metal near the probe is locally undercooled. However, this may need considerable numerical modeling, requiring very fine grid spacing around the fine probe to capture the temperature distribution in the nearby liquid. In metal casting the liquid is slightly superheated and there is no external heat source to maintain superheating during 
solidification. Thus, it is possible for solidification to occur on a sonotrode as big as $18 \mathrm{~mm}$ in diameter to act as a big heat sink. In arc welding, however, the weld pool is highly superheated by the arc continuously [1]. Since the probe is very close to the arc, very small in diameter $(0.5 \mathrm{~mm})$ and low in thermal conductivity, it can be expected to be heated above the liquidus temperature of the pool. Thus, it is unlikely that the liquid near the probe can be undercooled to cause nucleation of grains. This is confirmed by the columnar grains observed in the welds made by dipping the probe in the weld pool without ultrasonic oscillation.

No heat transfer analysis was conducted to confirm that the immersion of a very small $(0.5 \mathrm{~mm}$ diameter $)$ ultrasonic probe in the weld pool cannot cause local undercooling (which, if significant, may compete with the dendrite fragmentation due to vibration). However, direct temperature measurements with a thermal probe (i.e., a thermocouple) immersed in the weld pool have indicated no evidence of local undercooling at all. In the ongoing experiments in the welding lab of one of the authors (Kou), a thermocouple of $0.5 \mathrm{~mm}$ diameter (the same diameter as the ultrasonic probe) was immersed in the weld pool from the opposite side of the arc at a location behind the arc (the same way the ultrasonic probe was immersed in the weld pool, as shown in Fig. 1a). Instead of local undercooling, local superheating as much as 200 or $300^{\circ} \mathrm{C}$ was always measured. This is not surprising because the weld pool is so much superheated by the arc that the tip of a very small probe immersed in the pool is superheated by the pool instead of undercooling it.

Thus, the mechanism of grain refining is most likely dendrite fragmentation, 
instead of heterogeneous nucleation or grain detachment. Dendrite fragmentation is most effective if the probe is close to the mushy zone and the amplitude of oscillation is high. Ultrasonic stirring of the weld pool can also significantly reduce the temperature gradients in the pool to encourage the dendrite fragments to survive and grow into equiaxed grains.

\subsection{Effect of alloy composition on grain structure}

Ultrasonic stirring of the weld pool also caused significant grain refining in AZ91 $\mathrm{Mg}$ as can be seen in the optical micrographs in Fig. 9. In each micrograph the fusion boundary (indicated by an arrow) is near the right side, and the weld centerline is beyond the left side. The AZ91 Mg welds were wider than the AZ31 Mg welds (mainly because of the lower liquidus temperature of AZ91 Mg) and thus had to be cut off more than one half in order to keep the same photo size as AZ31 Mg. In fact, examination of the micrographs showed finer grains in AZ91 Mg than AZ31 Mg both

with and without ultrasonic stirring. The differences can be seen in Table 1 and by comparing Figs. 6 and 9.

StJohn et al. [33] showed that the grain size $d$ measured in castings of Mg alloys can be related to the alloy composition $C_{o}$ as follows:

$$
d=a+\frac{b}{Q}
$$

with

$$
Q=m_{L} C_{o}(k-1)
$$

where

$Q$ : growth restriction factor, 
$m_{L}$ : slope of the liquidus line of a binary phase diagram,

$k$ : equilibrium segregation coefficient.

For multi-component alloys with $i$ elements, such as AZ31 Mg and AZ91 Mg,

$$
Q=\Sigma_{1}^{i} m_{L i} C_{o i}\left(k_{i}-1\right)
$$

The physical meaning of the growth restriction factor $Q$ can be explained as follows. Based on both equilibrium and non-equilibrium solidification, Easton et al. [34] showed that $Q=\mathrm{d}\left(\Delta T_{c}\right) / \mathrm{d}\left(f_{S}\right)$ at $f_{S}=0$, where $\Delta T_{c}$ is constitutional supercooling (= the equilibrium liquidus temperature minus the actual liquid temperature) and the $f_{S}$ the fraction solid. In other words, $Q$ is the rate of development of constitutional supercooling $\Delta T_{c}$ with respect to the fraction solid $f_{S}$ at the beginning of growth. It was further shown that the growth of a previous grain generates sufficient constitutional supercooling to enable the nucleation event to occur at the next nucleant. The following equation was derived by StJohn et al. [35] to relate the grain size $d$ to $Q:$

$$
d=\frac{1}{\sqrt[3]{f N_{v}}}+5.6\left(\frac{D z \Delta T_{n}}{v Q}\right)
$$

where

$f$ : fraction of particles activated, $N_{v}$ : number density of particles, $D$ : diffusion coefficient of solute in melt, $z \Delta T_{n}$ : incremental amount of undercooling required for reestablishing the minimum undercooling for nucleation, $v$ : growth rate. 
The effect of the alloy composition on the grain size in the welds can be explained with the help of Eqs. (1) through (4). First consider the welds made without ultrasonic grain refining. As shown in Table 1, the grain size is $95 \mu \mathrm{m}$ for AZ31 Mg weld \#8 and much finer at $71 \mu \mathrm{m}$ for AZ91 Mg weld \#14. Both welds were made at $5.50 \mathrm{~mm} / \mathrm{s}(13 \mathrm{ipm})$ travel speed and 60 A current. As shown in Table 2, the growth restriction factor $Q$ is $18.4{ }^{\circ} \mathrm{C}$ for $\mathrm{AZ31} \mathrm{Mg}$ and much larger at $42.7{ }^{\circ} \mathrm{C}$ for $\mathrm{AZ91} \mathrm{Mg}$. The data for the liquidus slope $m_{L}$ and equilibrium segregation coefficient $k$ were taken from StJohn et al. [36]. Eq. (1) suggests the grain size $d$ decreases with increasing $Q$. Thus, the smaller grain size in AZ91 Mg weld \#14 seems consistent with Eq. (1) if other factors are close.

In a recent study by Babu and Cross [37], AZ31 Mg sheets were butt welded without ultrasonic stirring. Inserts of various $\mathrm{Al}$ contents were preplaced between the two sheets to be butt welded together in order to change the weld Al content. The grain size was found to decrease with increasing $\mathrm{Al}$ content in the weld. It also decreased with increasing $Q$, but at high $Q$ values there was a clear negative deviation from linearity.

Before leaving the discussion on the AZ91 Mg welds made without ultrasonic grain refining, it is worth mentioning that welds \#14 and 15 both show fine equiaxed grains along the fusion boundary, significantly finer than those in the bulk weld metal. In fact, AZ31 Mg weld \#8 made without ultrasonic grain refining seems to show a similar phenomenon. It is worth noting that Cross et al. [38] showed that the high undercooling $\Delta T$ associated with the low growth rate [39] at the fusion boundary can 
promote nucleation of fine equiaxed grains along the fusion boundary.

Now consider the effect of the alloy composition on the grain size in the welds made with ultrasonic grain refining. StJohn et al. [35] pointed out that in Eq. (4) the fraction of particles activated $f$ is a function of ultrasound amplitude $A$, that is, $f(A)$. The higher the amplitude $A$ is, the higher $f(A)$ becomes and the smaller the grain size d. As shown in Table 1, the average grain size of AZ91 Mg weld \#16 (Fig. 9c) made at $3 \mathrm{~mm}$ offset and $26.44 \mu \mathrm{m}$ amplitude is $34 \mu \mathrm{m}$. For comparison, the average grain size of AZ31 Mg weld \#12 (Fig. 6c) made at $7 \mathrm{~mm}$ offset and $26.44 \mu \mathrm{m}$ amplitude is $46 \mu \mathrm{m}$. It is recognized that the travel speed was $6.35 \mathrm{~mm} / \mathrm{s}$ for AZ91 Mg weld \#16 and $5.50 \mathrm{~mm} / \mathrm{s}$ for AZ31 Mg weld \#12. However, the difference is small. So, AZ91 Mg weld \#16 is still significantly finer than the AZ31 Mg weld \#12 even though the much larger offset of the latter helped grain refining. Thus, as in the case of no ultrasonic stirring, the effect of alloy composition on the grain size through $Q$ is clear.

\subsection{Effect of travel speed on grain structure}

Compare AZ31 Mg welds \#7 and \#11 in Table 1, which were made under identical conditions of welding and ultrasonic stirring except for the travel speed. The former was made at $4.23 \mathrm{~mm} / \mathrm{s}$ (10 ipm) and the average grain size was $52 \mu \mathrm{m}$, while the latter was made at $5.50 \mathrm{~mm} / \mathrm{s}(13 \mathrm{ipm})$ and the average grain size was $48 \mu \mathrm{m}$. Along the centerline of the weld, the travel speed can be considered the same as the growth rate if the effect of the crystal orientation is ignored [1]. The effect of travel speed on the grain size is consistent with Eq. (4) in the sense that the grain size $d$ decreases with increasing growth rate $v$. However, the effect is not strong. Similar 
effect of the travel speed can be seen by comparing the two AZ91 Mg welds made without ultrasonic stirring. As shown in Table 1, weld \#14 was made at $5.50 \mathrm{~mm} / \mathrm{s}$ (13 ipm) and the average grain size was $71 \mu \mathrm{m}$, while weld $\# 15$ was made at $6.35 \mathrm{~mm} / \mathrm{s}$ (15 ipm) and the average grain size was $63 \mu \mathrm{m}$. Again, the effect of travel speed is not strong.

\section{Conclusions}

(1) Effective grain refining can be achieved in welding by ultrasonic stirring of the weld pool with a probe positioned behind the arc, as demonstrated in arc welding of $\mathrm{Mg}$ alloys $\mathrm{AZ31} \mathrm{Mg}$ and $\mathrm{AZ91} \mathrm{Mg}$.

(2) Positioning the probe farther behind the arc can increase grain refining. The initial crystallites or dendrite fragments might have a better chance to survive if they are generated by ultrasonic stirring in a cooler area farther behind the arc. Since a probe farther behind the arc is closer to the mushy zone, it is also more likely to cause dendrite fragmentation.

(3) However, a probe too far behind the arc can be inside the mushy zone to cause highly non-uniform grain refining, with extra-fine grains near the weld centerline (where the probe is located) but no grain refining elsewhere in the weld.

(4) Grains tend to be significantly finer in AZ91 Mg welds than AZ31 Mg welds. And this is true with or without ultrasonic stirring. The higher solute content of AZ91 $\mathrm{Mg}$ causes more constitutional supercooling to develop and promotes nucleation.

(5) Increasing the ultrasound amplitude increases grain refining. 


\section{Acknowledgements}

The authors gratefully acknowledge the support of the National Science

Foundation of the United States under Grant No. DMR 1500367 and the University of

Wisconsin Foundation. The financial support by the China Scholarship Council for

Tao Yuan to work as a visiting graduate student at UW-Madison is also acknowledged.

The authors would like to thank Professor Hongmin Guo of Nanchang University,

China, and Jiangwei Liu, Kai Narita, and Tayfun Soysal for their help with the weld

microstructure.

\section{References}

[1] S. Kou, Welding Metallurgy, second ed., John Wiley, Hoboken, New Jersey, 2003.

[2] N. K. Babu and C. E. Cross, Grain refinement of AZ31 magnesium alloy weldments by AC pulsing technique, Metall. Mater. Trans. A 43A (2012) 4145-4154.

[3] S. R. K. Rao, G. Madhusudhana Reddy, M. Kamaraj, K. P. Rao, Grain refinement through arc manipulation techniques in Al-Cu alloy GTA welds, Mater. Sci. Eng. A 404 (2005) 227-234.

[4] S. Kou and Y. Le, Grain structure and solidification cracking in oscillated arc welds of 5052 aluminum alloy, Metall. Trans. A 16A (1985) 1345.

[5] P. Schempp, A. Pittner, M. Rethmeier, Z. Tang, T. Seefeld and C. E. Cross, Influence of alloy and solidification on grain refinement in aluminum weld metal due to inoculation, in Trends in Welding Research, Proceedings of the $9^{\text {th }}$ International Conference, June 4-8, Chicago, IL, 2012, ASM International, 2013, pp. 98-107.

[6] S. Sundaresan, G. D. Janaki Ram, R. Murugesan, and N. Viswanathan, Combined effect of inoculation and magnetic arc oscillation on microstructure and tensile behaviour of type 2090 Al-Li alloy weld fusion zones, Sci. Technol. Weld. Joining 5 (2000) 257.

[7] N. K. Babu, M. K. Talari, D. Pana, Z. Sun, J. Wei, K. Sivaprasad, Microstructural characterization and grain refinement of AA6082 gas tungsten arc welds by scandium modified fillers, Mater. Chem. Phys. 137 (2012) 543-551.

[8] B. P. Pearce, H. W Kerr, Grain refinement in magnetically GTA welds of aluminum alloys stirred GTA welds of aluminum alloys, Metall. Trans. B 12B (1981) 479.

[9] Matsuda, F., Ushio, M., Nakagawa, H., and Nakata, K. Effects of electromagnetic stirring on the weld solidification structure of aluminum alloys, Arc Physics and 
Weld Pool Behavior, The Welding Institute, Cambridge, U.K., 1979, pp. 337-347.

[10]L. He, M. Wu, L. Li and H. Hao, Ultrasonic generation by exciting electric arc: a tool for grain refinement in welding process, Appl. Phys. Lett. 89 (2006) 131504.

[11]W. Dai, Effects of high-intensity ultrasonic-wave emission on the weldability of aluminum alloy 7075-T6, Mater. Lett. 57 (2003) $2447-2454$.

[12]Y. Cui, C. Xu and Q. Han, Microstructure improvement in weld metal using ultrasonic vibrations, Adv. Eng. Mate. 9 (2007) 161-163.

[13]Y. Cui, C. L. Xu and Q. Han, Effect of ultrasonic vibration on unmixed zone formation, Scripta Mater. 55 (2006) 975-978.

[14]G. I. Eskin, Ultrasonic treatment of light alloy melts, Gordon and Breach, Amsterdam, 1998, pp. 1-25, 135-240.

[15]T. Watanabe, M. Shiroki, A. Yanagisawa, and T. Sasaki, Improvement of mechanical properties of ferritic stainless steel weld metal by ultrasonic vibration, J. Mater. Process. Technol. 210 (2010) 1646-1651.

[16]A. Luo, Processing, microstructure, and mechanical behavior of cast magnesium metal matrix composites, Metall. Mater. Trans. A. 26A (1995) 2445-2455.

[17]A. Stevenson: Metals Handbook, ASM International, Materials Park, OH, 1989, vol. 4, p.899.

[18]ASTM E112. 2004. Standard Test Methods for Determining Average Grain Size. ASTM.

[19]S. Kou and Y. Le, Nucleation mechanisms and grain refining of weld metal, Welding J. 65 (1986) 305-s.

[20]V. Abramov, O. Abramov, V. Bulgakov and F. Sommer, Solidification of aluminum alloys under ultrasonic irradiation using water-cooled resonator, Mater. Lett. 37 (1998) 27-34.

[21]D. Shu, B. Sun, J. Mi and P. Grant, A high-speed imaging and modeling study of dendrite fragmentation caused by ultrasonic cavitation, Metall. Mater. Trans. A 43A (2012) 3755-3765.

[22]J. Li, T. Momono, Y. Fu, Z. Jia, Y. Tayu, Effect of ultrasonic stirring on temperature distribution and grain refinement in $\mathrm{Al}-1.65 \% \mathrm{Si}$ alloy melt, Trans. Nonferrous Met. SOC. China 17(2007) 691-697.

[23]B. Chalmers, Principles of Solidification, John Wiley and Sons, New York, 1964.

[24]J. Campbell, Effects of vibration during solidification, Int. Met. Rev. 26 (1981) 71-108.

[25]A. Ramirez, M. Qian, B. Davis, T. Wilks and D. H. StJohn, Potency of high-intensity ultrasonic treatment for grain refinement of magnesium alloys, Scripta Mater. 59 (2008) 19-22.

[26]X. Liu, Y. Osawa, S. Takamori and T. Mukai, Grain refinement of AZ91 alloy by introducing ultrasonic vibration during solidification, Mater. Lett. 62 (2008) 2872-2875.

[27]M. Qian, A. Ramirez, A. Das, D. H. StJohn, The effect of solute on ultrasonic grain refinement of magnesium alloys, J. Crystal Growth 312 (2010) 2267-2272.

[28]S. Kou, Transport Phenomena and Materials Processing, John Wiley, Hoboken, New Jersey, 1996. 
[29]Pandat, Phase Diagram Calculation Software Package for Multicomponent Systems, Computherm LLC, Madison, WI, 2013.

[30]PanMagnesium, Thermodynamic Database for Magnesium Alloys, Computherm LLC, Madison, WI, 2013.

[31]D. A. Porter, K. E. Easterling and M. Y. Sherif, Phase Transformations in Metals and Alloys, $3^{\text {rd }}$ ed., CRC Press, 1980, 188-192.

[32] G. Wang, M. S. Dargusch, M. Qian, D. G. Eskin and D. H. StJohn, The role of ultrasonic treatment in refining the as-cast grain structure during the solidification of an Al-2Cu alloy, J. Crystal Growth, 408 (2014) 119-124.

[33]D. H. StJohn, P. Cao, M. Qian, M. A. Easton, A new analytical approach to reveal the mechanisms of grain refinement, Adv. Eng. Mater. 6 (2007) 739-746.

[34]M. A. Easton, D. H. StJohn, A model of grain refinement incorporating alloy constitutional and potency of heterogeneous nucleant particles, Acta Mater. 49 (2001) 1867-1878.

[35]D. H. StJohn, M. A. Easton, M. Qian, J. A. Taylor, Grain refinement of magnesium alloys: A review of recent research, theoretical developments, and their application, Metall. Mater. Trans. A 44A (2013) 2935-2949.

[36]D. H. StJohn, M. Qian, M. A. Easton, P. Cao, and Z. Hildebrand, Grain refinement of magnesium alloys, Metall. Mater. Trans. A 36A (2005) 1669-1679.

[37]N. K. Babu and C. E. Cross, Influence of aluminum content on grain refinement and strength of AZ31 magnesium GTA weld metal, in Trends in Welding Research, Proceedings of the $9^{\text {th }}$ International Conference, June 4-8, Chicago, IL, 2012, ASM International, 2013, pp. 91-97.

[38]C. E. Cross, O. Grong and M. Mousavi, A model for equiaxed grain formation along the weld metal fusion line, Scripta Mater. 40 (1999) 1139-1144.

[39] J. D. Hunt, Steady-state columnar and equiaxed growth of dendrites and eutectic, Mater. Sci. Eng. 65 (1984) 75-83. 
Table 1 Welds made under various conditions of welding and ultrasonic stirring

\begin{tabular}{|c|c|c|c|c|c|c|c|}
\hline Alloy & Weld \# & $\begin{array}{l}\text { Current } \\
\text { (A) }\end{array}$ & $\begin{array}{l}\text { Travel speed } \\
(\mathrm{mm} / \mathrm{s})\end{array}$ & $\begin{array}{l}\text { Offset } \\
(\mathrm{mm})\end{array}$ & $\begin{array}{l}\text { Amplitude } \\
\qquad(\mu \mathrm{m})\end{array}$ & $\begin{array}{c}\text { Refined } \\
\text { grain } \\
\text { size }(\mu \mathrm{m}) \\
(\text { except } \\
\# 8,14,15)\end{array}$ & $\begin{array}{c}\text { Area } \\
\text { fraction of } \\
\text { refined } \\
\text { grains }(\%)\end{array}$ \\
\hline \multirow{13}{*}{ AZ31 } & 1 & 60 & $5.50(13 \mathrm{ipm})$ & 4 & 0 & 0 & 0 \\
\hline & 2 & 60 & $4.23(10 \mathrm{ipm})$ & 0 & 26.44 & 75 & 26 \\
\hline & 3 & 60 & $4.23(10 \mathrm{ipm})$ & 5 & 14 & 63 & 28 \\
\hline & 4 & 60 & $4.23(10 \mathrm{ipm})$ & 5 & 17.11 & 63 & 40 \\
\hline & 5 & 60 & $4.23(10 \mathrm{ipm})$ & 5 & 20.22 & 60 & 53 \\
\hline & 6 & 60 & $4.23(10 \mathrm{ipm})$ & 5 & 23.33 & 53 & 70 \\
\hline & 7 & 60 & $4.23(10 \mathrm{ipm})$ & 6 & 26.44 & 52 & 87 \\
\hline & 8 & 60 & 5.50 (13 ipm) & \multicolumn{2}{|c|}{ no oscillation } & 95 & 0 \\
\hline & 9 & 60 & $5.50(13 \mathrm{ipm})$ & 4 & 26.44 & 55 & 86 \\
\hline & 10 & 60 & $5.50(13 \mathrm{ipm})$ & 5 & 26.44 & 51 & 90 \\
\hline & 11 & 60 & 5.50 (13 ipm) & 6 & 26.44 & 48 & 96 \\
\hline & 12 & 60 & 5.50 (13 ipm) & 7 & 26.44 & 46 & 100 \\
\hline & 13 & 60 & 5.50 (13 ipm) & 8 & 26.44 & 31 & 30 \\
\hline \multirow{3}{*}{ AZ91 } & 14 & 60 & 5.50 (13 ipm) & \multicolumn{2}{|c|}{ no oscillation } & 71 & 0 \\
\hline & 15 & 60 & $6.35(15 \mathrm{ipm})$ & \multicolumn{2}{|c|}{ no oscillation } & 63 & 0 \\
\hline & 16 & 60 & $6.35(15 \mathrm{ipm})$ & 3 & 26.44 & 34 & 88 \\
\hline
\end{tabular}

Table 2 Values of $Q$ calculated based on Eq. (3) and $m_{L}$ and $k$ from StJohn et al. [36]

\begin{tabular}{|c|c|c|c|c|c|}
\hline Alloy & $\begin{array}{c}\mathrm{Al} \\
(\mathrm{wt} \%)\end{array}$ & $\begin{array}{c}\mathrm{Zn} \\
(\mathrm{wt} \%)\end{array}$ & $\begin{array}{c}\mathrm{Mn} \\
(\mathrm{wt} \%)\end{array}$ & $\begin{array}{c}\mathrm{Mg} \\
(\mathrm{wt} \%)\end{array}$ & $\begin{array}{c}Q \\
\left({ }^{\circ} \mathrm{C}\right)\end{array}$ \\
\hline$m_{L}\left({ }^{\circ} \mathrm{C} / \mathrm{wt} \%\right)$ & -6.87 & -6.04 & 1.49 & & \\
\hline$k$ & 0.37 & 0.12 & 1.10 & & \\
\hline $\mathrm{AZ31}$ & 3.0 & 1.0 & 0.6 & balance & 18.4 \\
\hline $\mathrm{AZ91}$ & 9.0 & 0.7 & 0.2 & balance & 42.7 \\
\hline
\end{tabular}




\section{Figure captions}

Fig.1 Schematic sketches illustrating grain refining during welding: (a) vertical longitudinal cross-section along weld centerline showing ultrasonic stirring of weld pool; (b) horizontal longitudinal cross-section; (c) possible mechanisms of grain refining. In (a) the workpiece alone travels and the direction of travel is indicated by the arrowhead.

Fig. 2 Example of weld macrograph.

Fig. 3 Normal optical micrographs of weld \# 1: (a) horizontal longitudinal cross-section showing no grain refining at $4 \mathrm{~mm}$ offset and $0 \mu \mathrm{m}$ amplitude; (b) transverse cross-section. White arrowheads: fusion boundaries (weld edges). Dark arrowhead: travel direction of workpiece.

Fig 4 Polarized-light micrographs of welds: (a) horizontal longitudinal cross-section of weld \#1 showing no grain refining at $4 \mathrm{~mm}$ offset and $0 \mu \mathrm{m}$ amplitude; (b) transverse cross-section of weld \#1; (c) transverse cross-section of weld \#9 showing grain refining by oscillation at $4 \mathrm{~mm}$ offset and $26.44 \mu \mathrm{m}$ amplitude.

Fig. 5 Polarized-light micrographs showing horizontal longitudinal cross-sections of AZ31 Mg welds and effect of amplitude of ultrasonic stirring on grain structure:

(a) $14.00 \mu \mathrm{m}$; (b) $17.11 \mu \mathrm{m}$; (c) $23.33 \mu \mathrm{m}$; (d) $26.44 \mu \mathrm{m}$. Offset: $5 \mathrm{~mm}$ in (a) through (c) and $6 \mathrm{~mm}$ in (d).

Fig. 6 Polarized-light micrographs showing horizontal longitudinal cross-sections of AZ31 Mg welds and effect of probe position (offset) on grain structure: (a) no 
ultrasonic stirring; (b) $4 \mathrm{~mm}$ offset; (c) $7 \mathrm{~mm}$ offset; (d) $8 \mathrm{~mm}$ offset. Amplitude: $26.44 \mu \mathrm{m}$.

Fig. 7 SEM images showing horizontal longitudinal cross-sections of welds and effect of grain refining: (a) some grain refining with small offset and amplitude; (b) extensive grain refining with large offset and amplitude; (c) probe inside mushy zone due to excessive offset, causing grain refining, though very effective, to be limited to near weld centerline; (d) SEM image of equiaxed grains in weld \#12; (e) SEM image of columnar grains in weld \#13; (f) SEM image of equiaxed grains in weld \#13.

Fig. 8 Curves of temperature vs. fraction solid showing formation of intermetallic compounds during solidification of: (a) AZ31 Mg; (b) AZ91 Mg. The curves were calculated using Pandat [29] and PanMagnesium [30] of CompuTherm.

Fig. 9 Normal optical micrographs showing horizontal longitudinal cross-sections of AZ91 Mg welds: (a) no stirring, $5.50 \mathrm{~mm} / \mathrm{s}$ travel speed; (b) no stirring, 6.35 $\mathrm{mm} / \mathrm{s}$ travel speed; (c) $26.44 \mu \mathrm{m}$ amplitude, $3 \mathrm{~mm}$ offset, $6.35 \mathrm{~mm} / \mathrm{s}$ travel speed. 

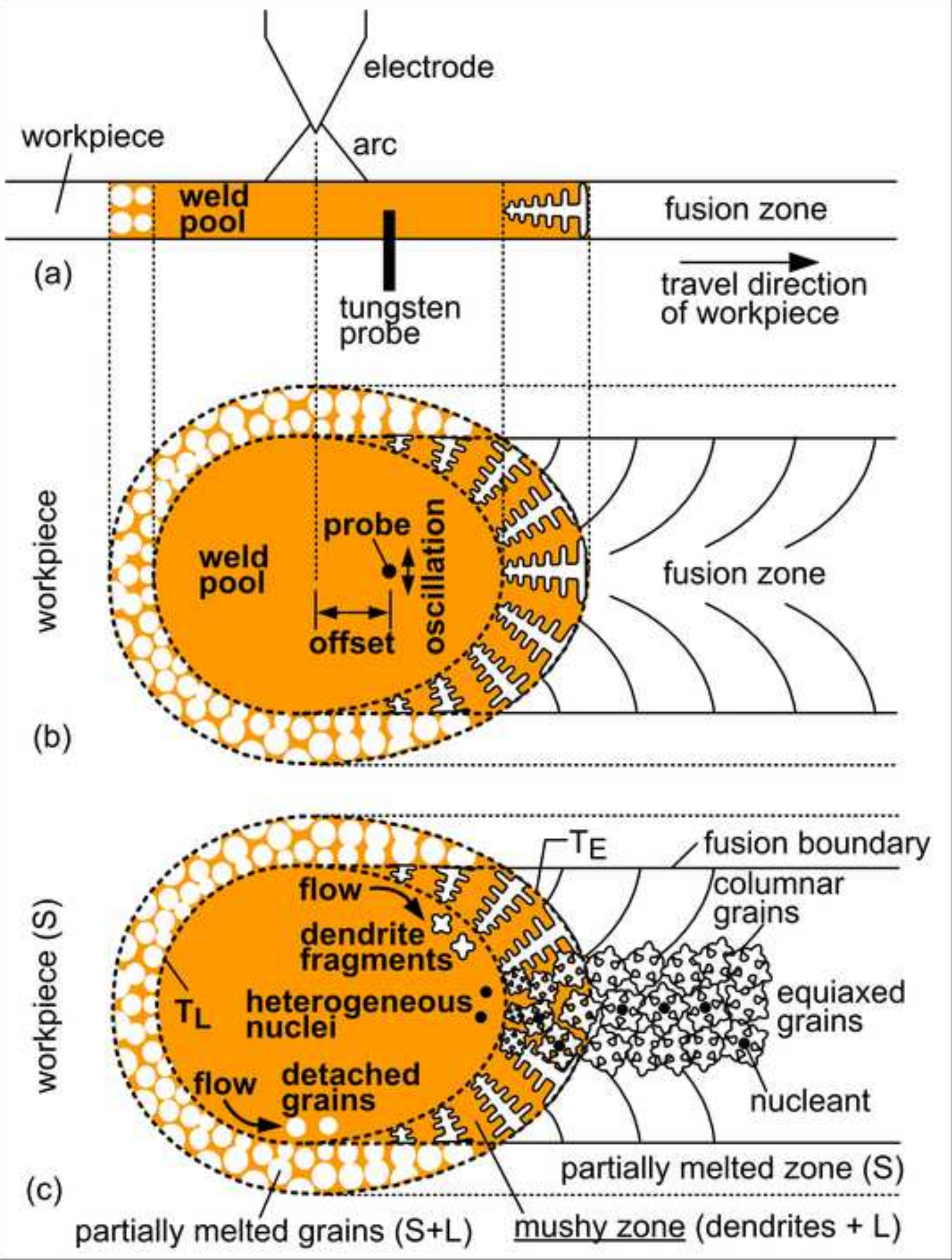




\section{probe dipped in pool}

travel direction of workpiece

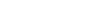


AZ31 weld \#1 longitudinal cross-section; probe not oscillated (4 mm offset)

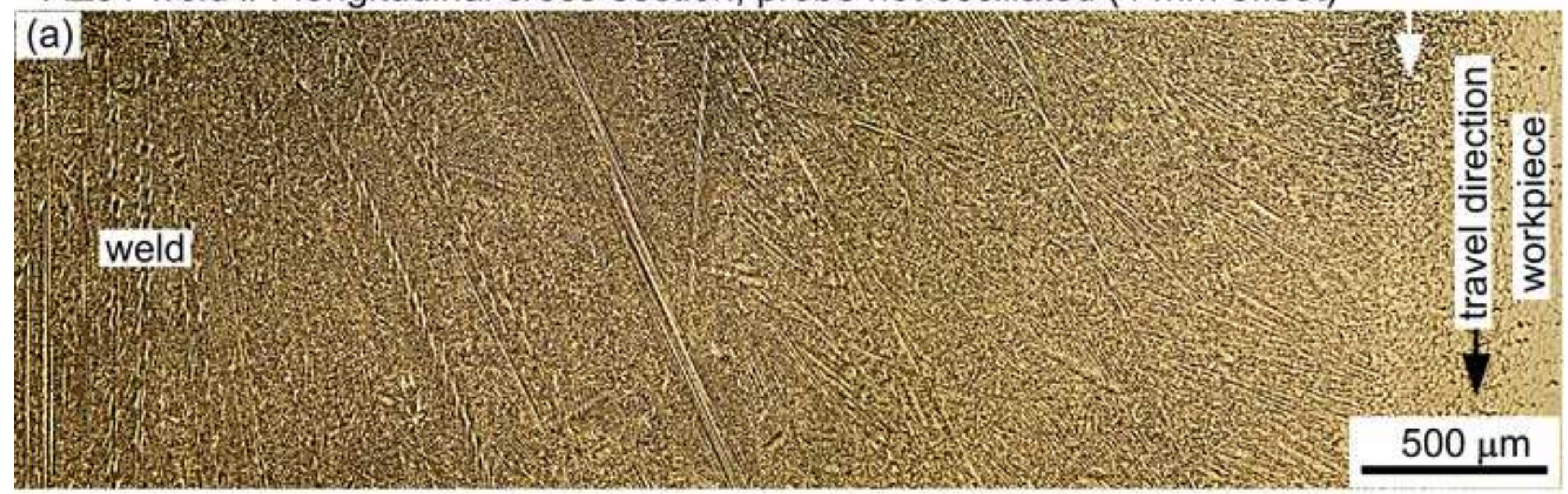

\section{Transverse cross-section}

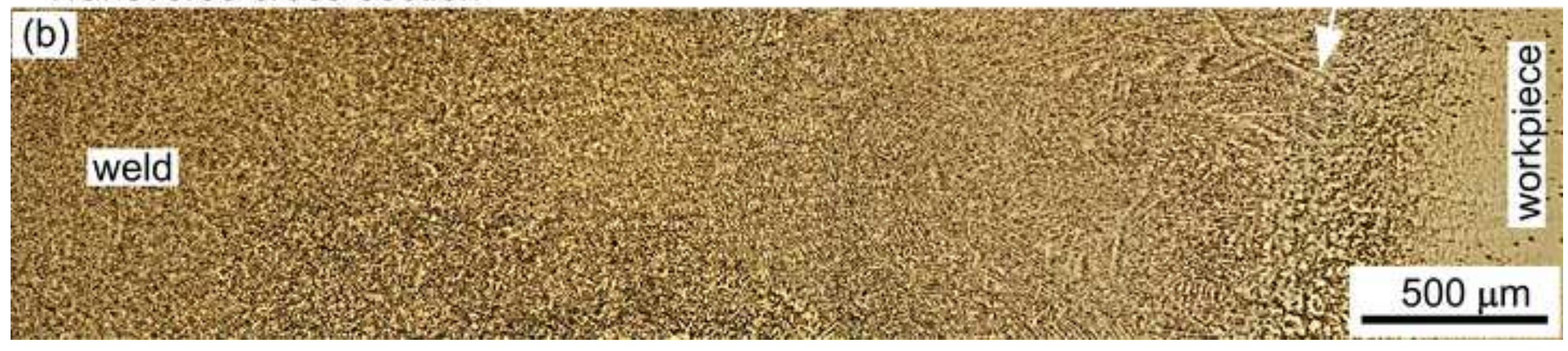


AZ31 weld \#1 longitudinal cross-section; $4 \mathrm{~mm}$ offset; no oscillation; no grain refining

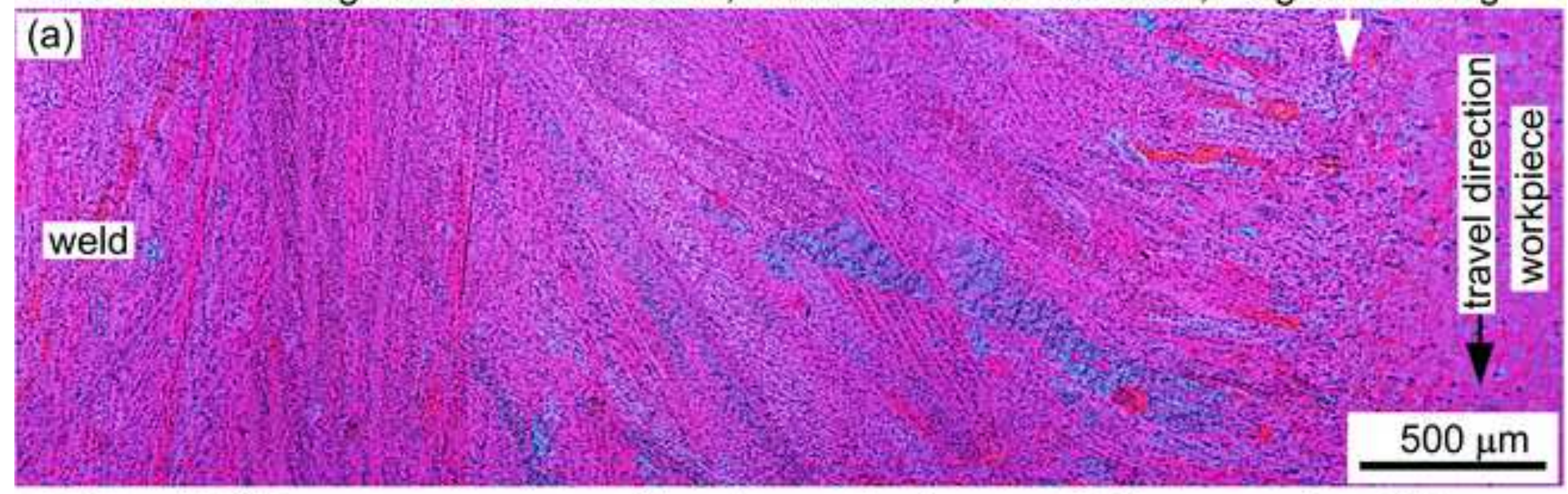

AZ31 weld \#1 transverse cross-section; $4 \mathrm{~mm}$ offset; no oscillation; no grain refining

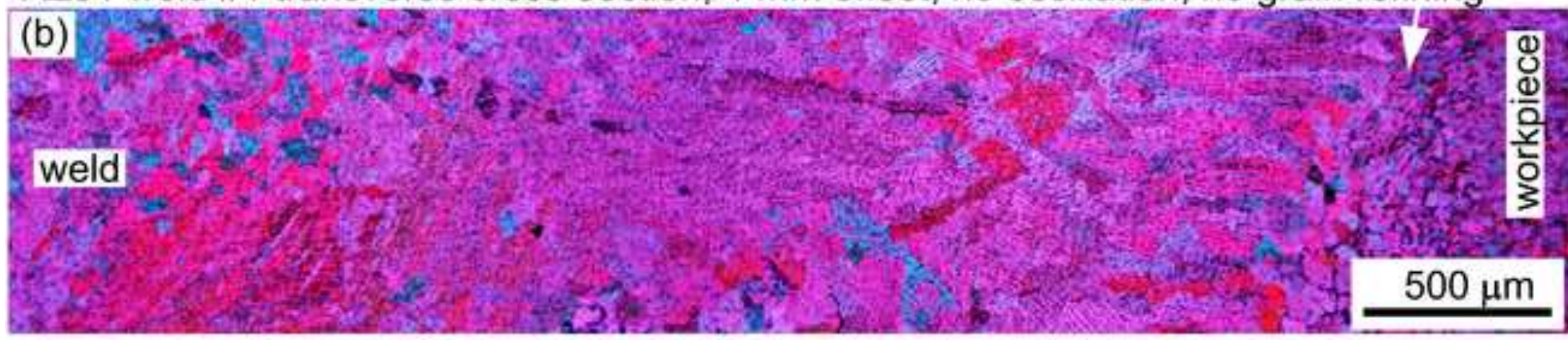

AZ31 weld \#9 transverse cross-section; $4 \mathrm{~mm}$ offset, oscillation; grain refining

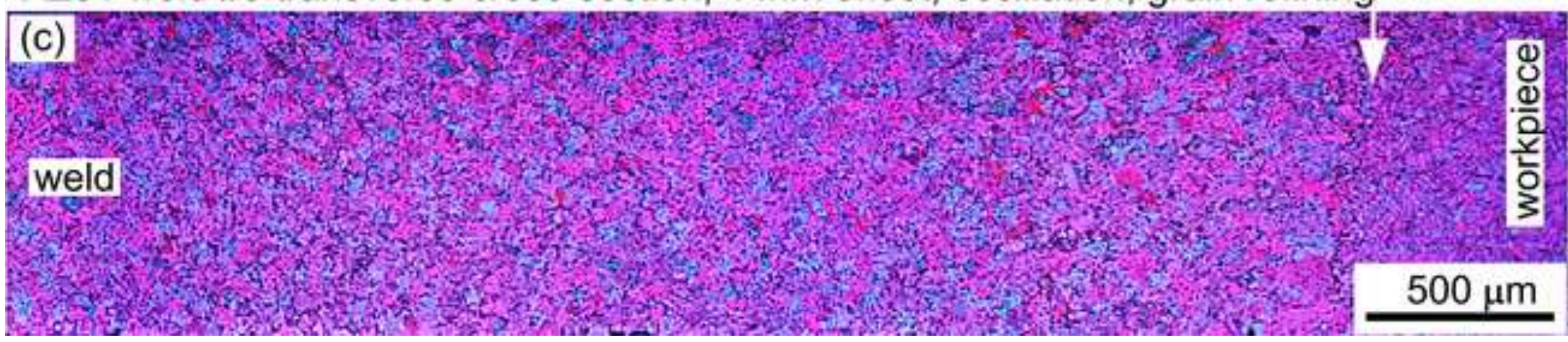


AZ31 weld \#3: $14.00 \mu \mathrm{m}$ amplitude; least grain refining

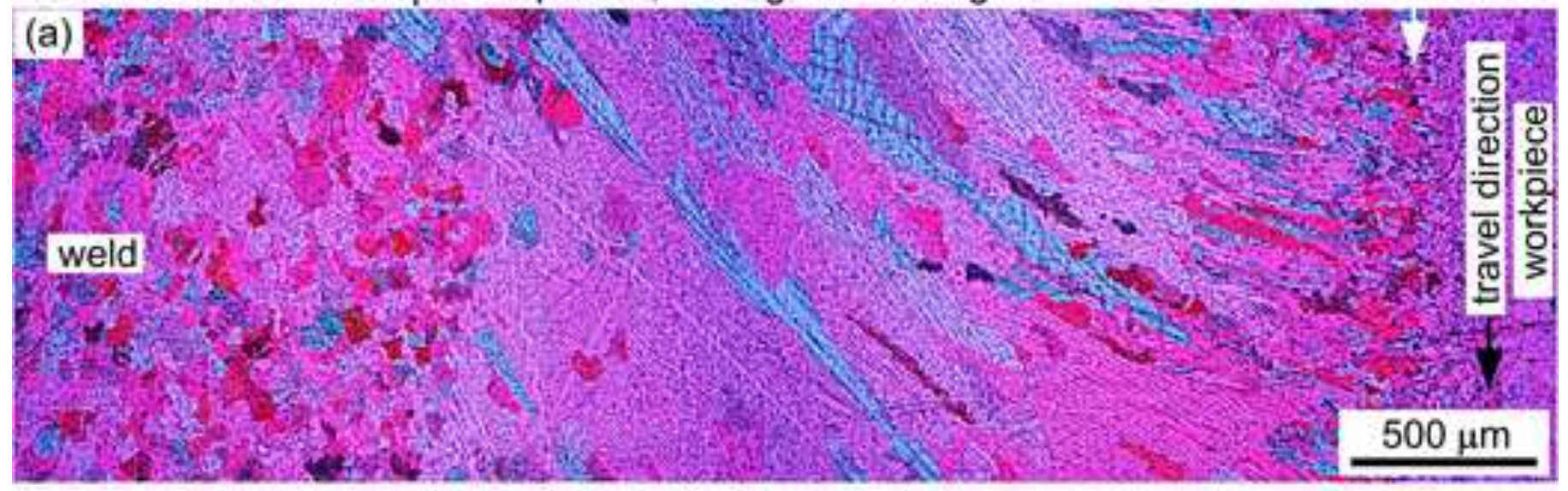

AZ31 weld \#4: $17.11 \mu \mathrm{m}$ amplitude; some grain refining

(b)
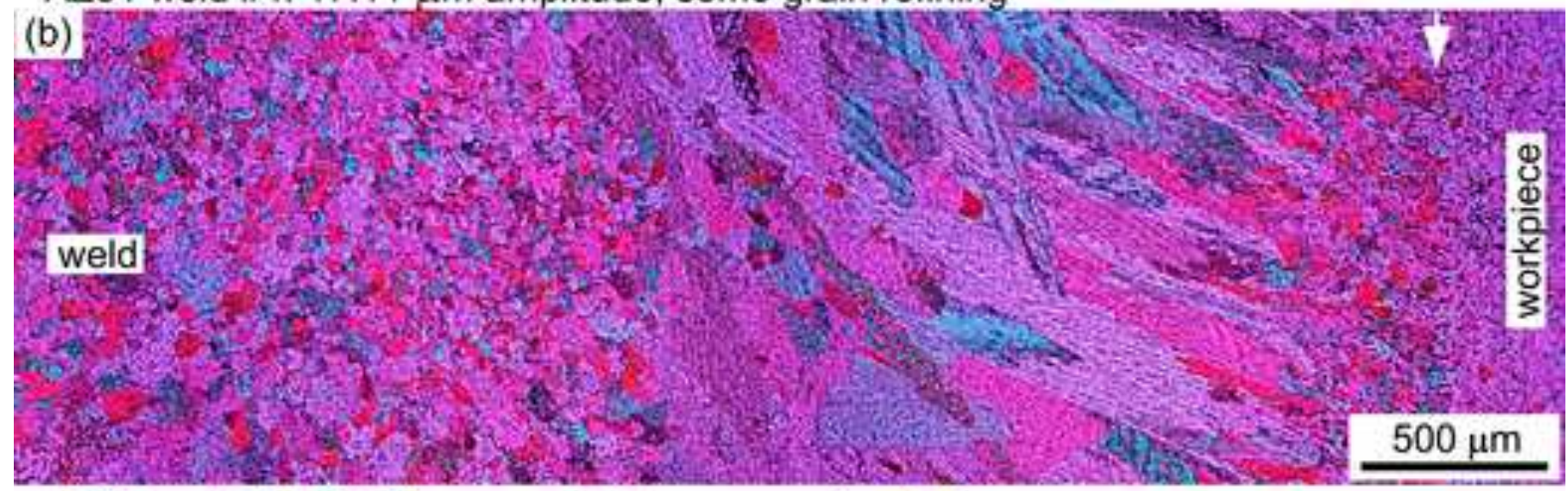

AZ31 weld \#6: $23.33 \mu \mathrm{m}$ amplitude; more grain refining

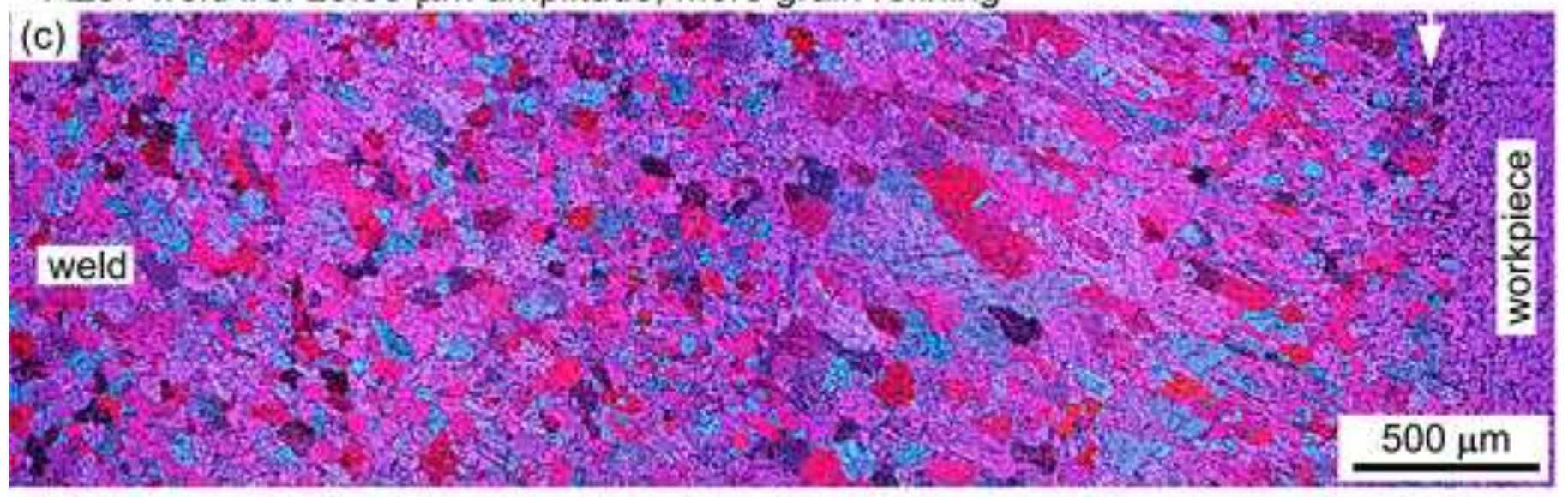

AZ31 weld \#7: $26.44 \mu \mathrm{m}$ amplitude; most grain refining

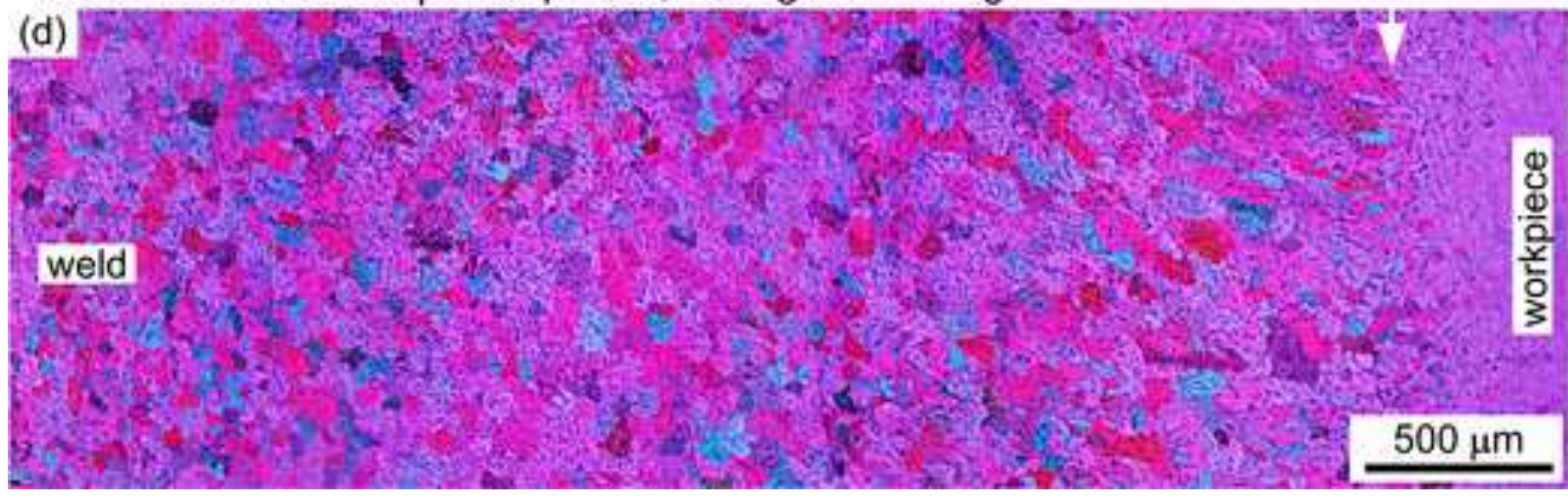


AZ31 weld \#8: no ultrasonic stirring; no grain refining

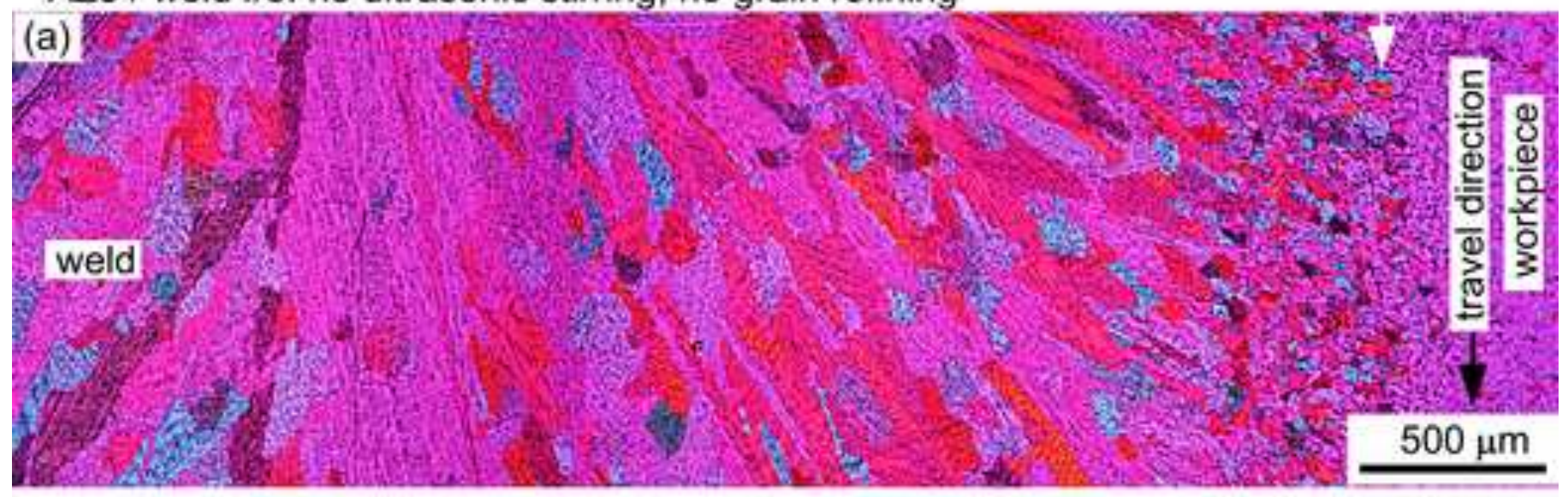

AZ31 weld \#9: probe $4 \mathrm{~mm}$ behind arc; good grain refining

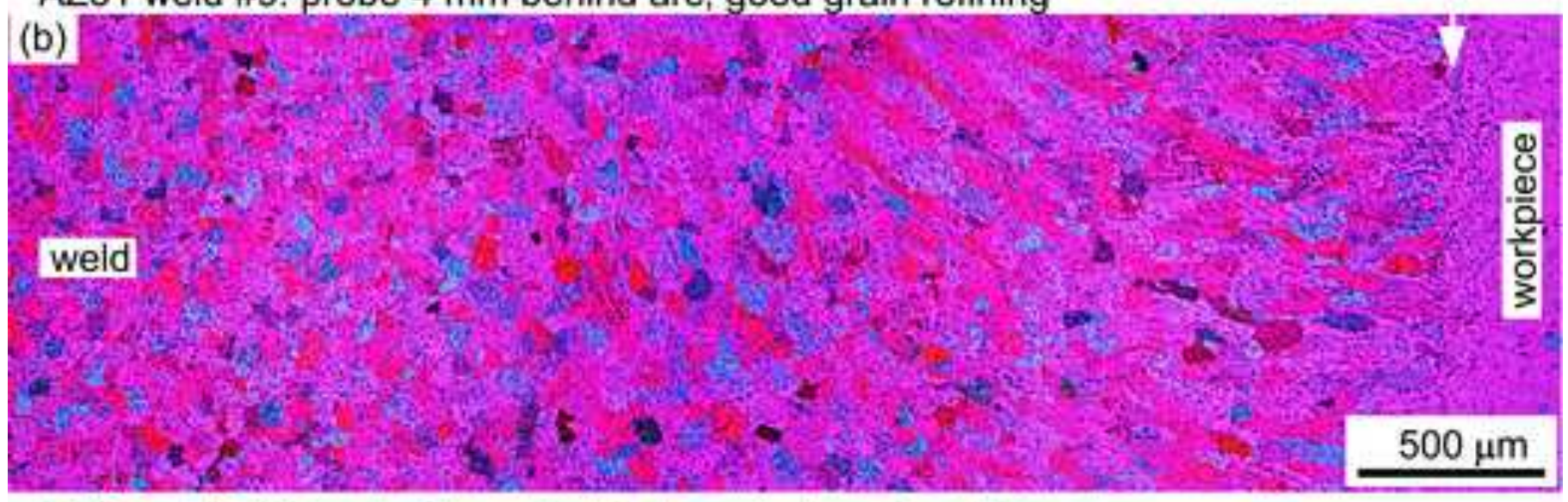

AZ31 weld \#12: probe $7 \mathrm{~mm}$ behind arc; best grain refining

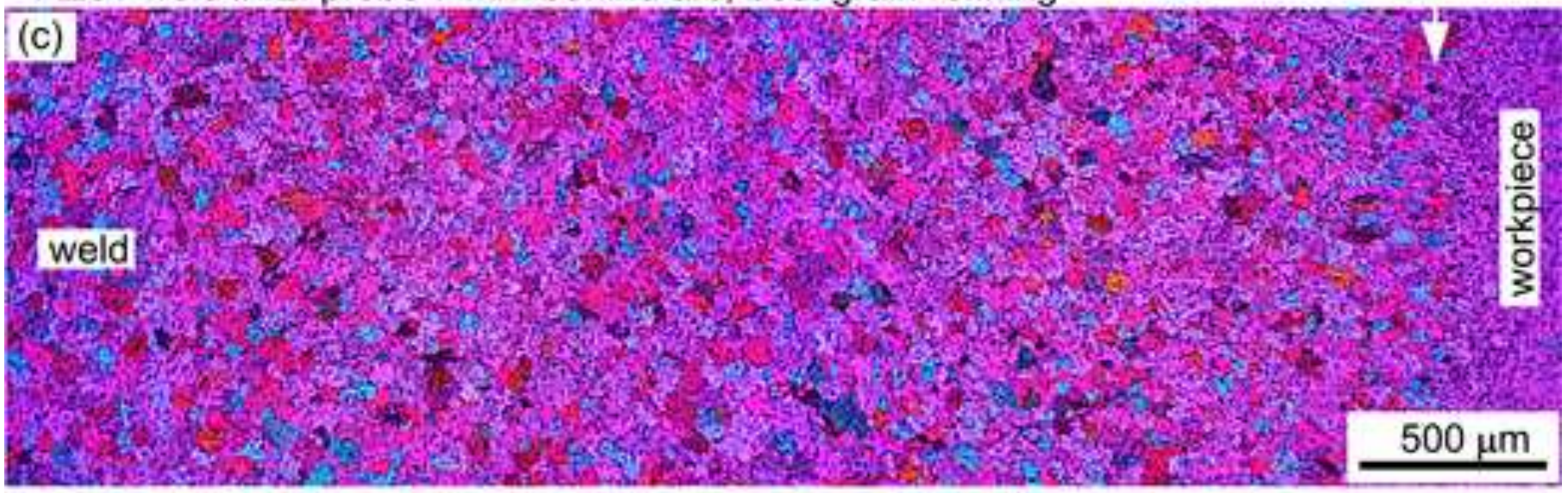

AZ31 weld \#13: probe $8 \mathrm{~mm}$ behind arc; very fine grains but only near centerline

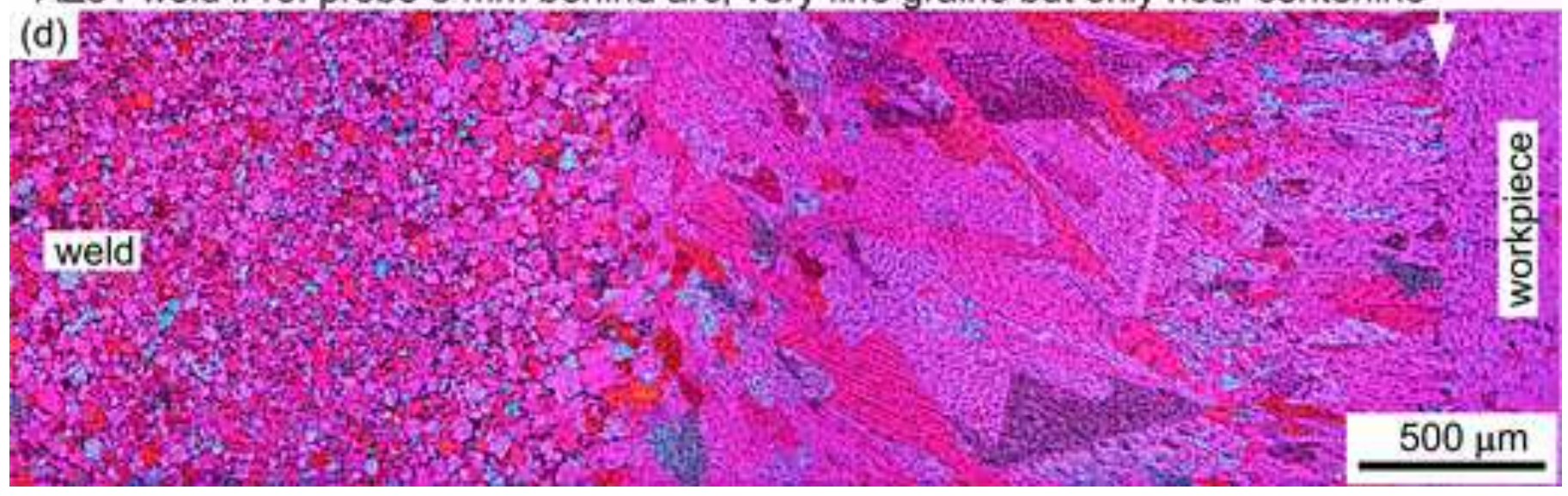




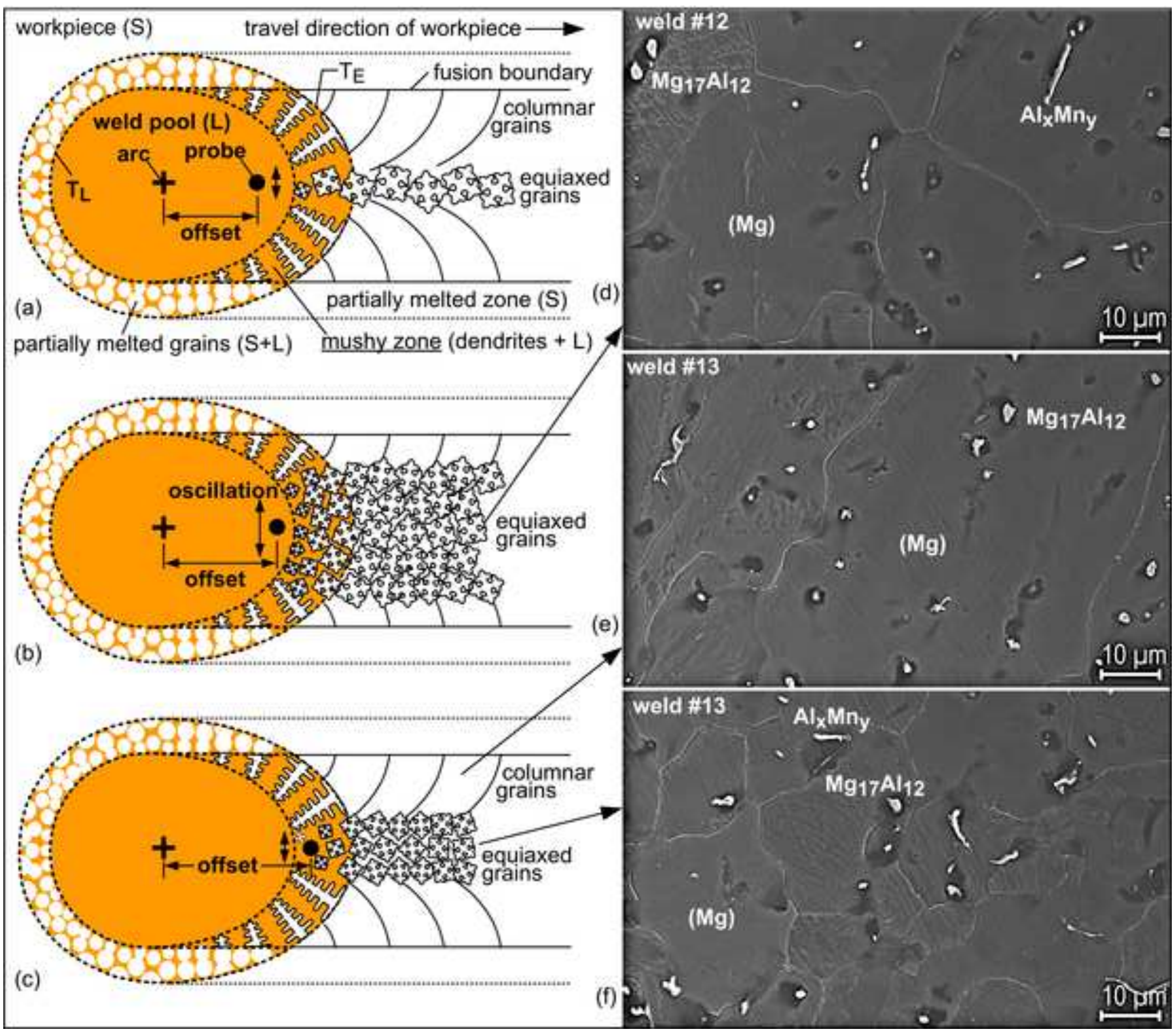




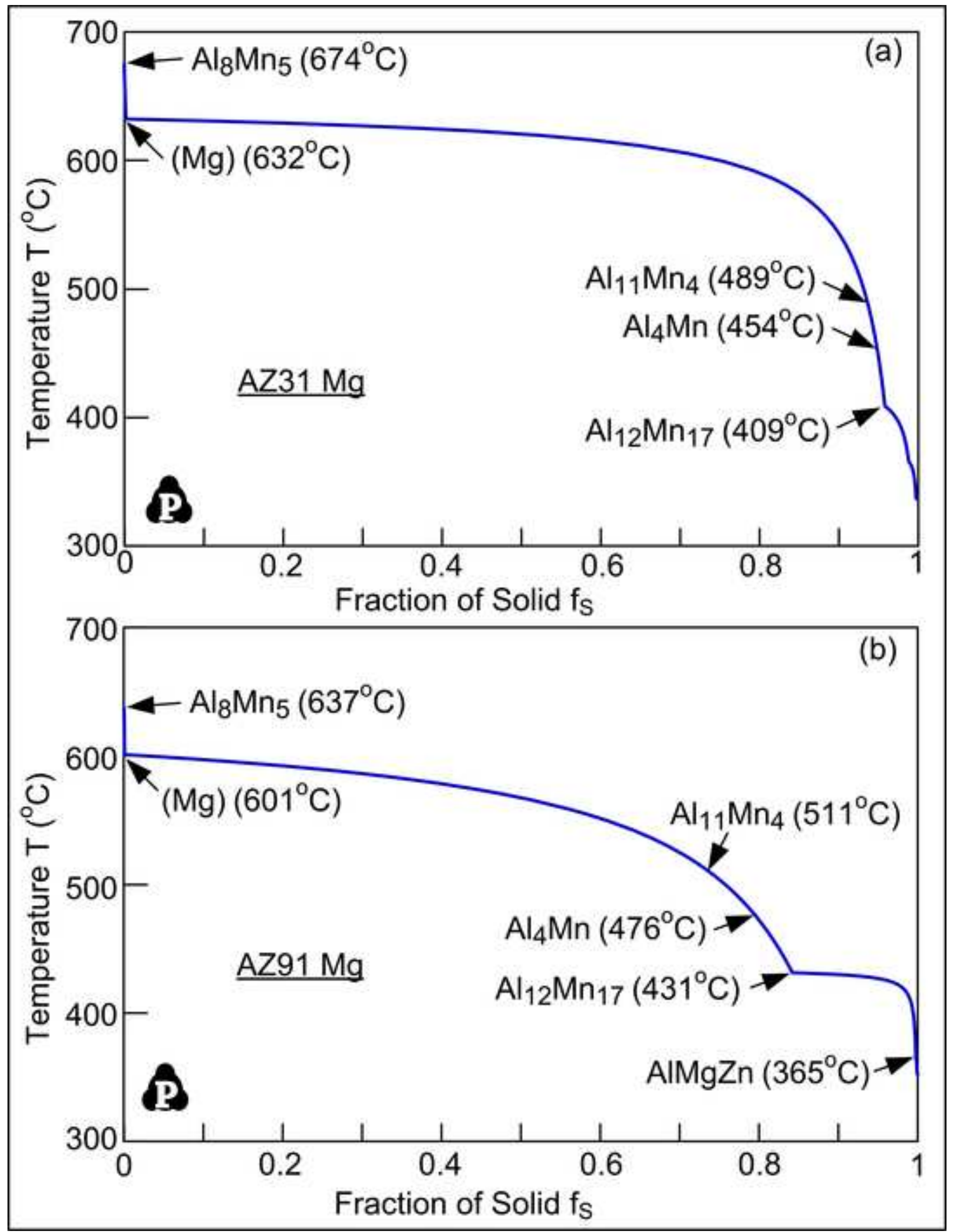


AZ91 weld \#14: no ultrasonic stirring; no grain refining

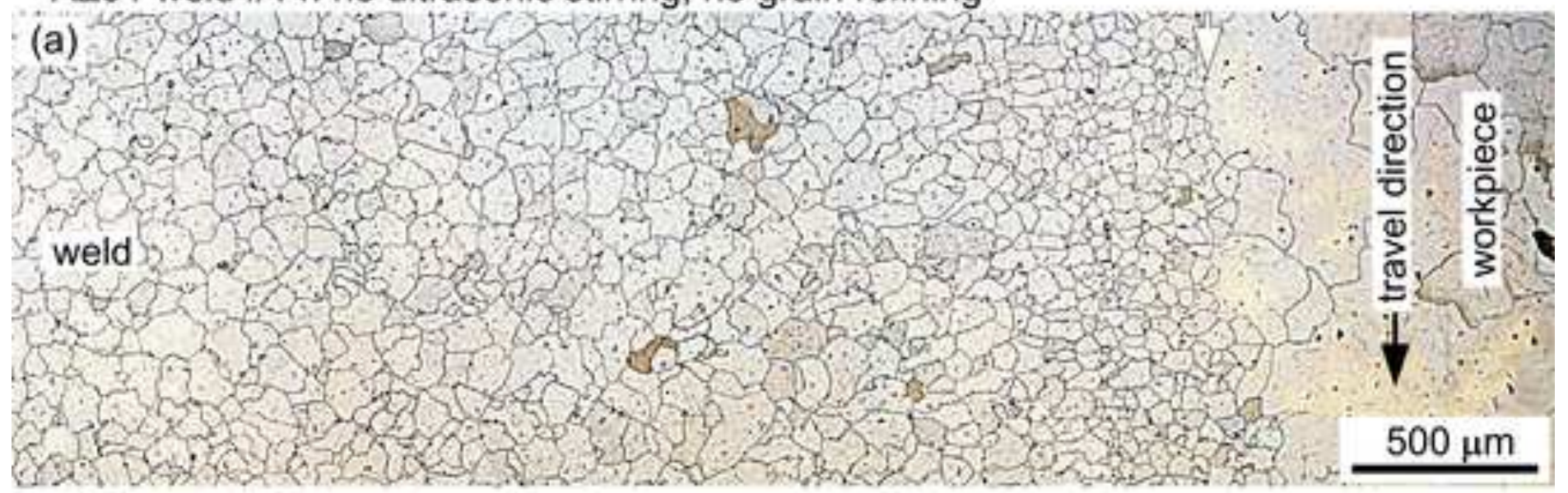

AZ91 weld \#15: no ultrasonic stirring; no grain refining

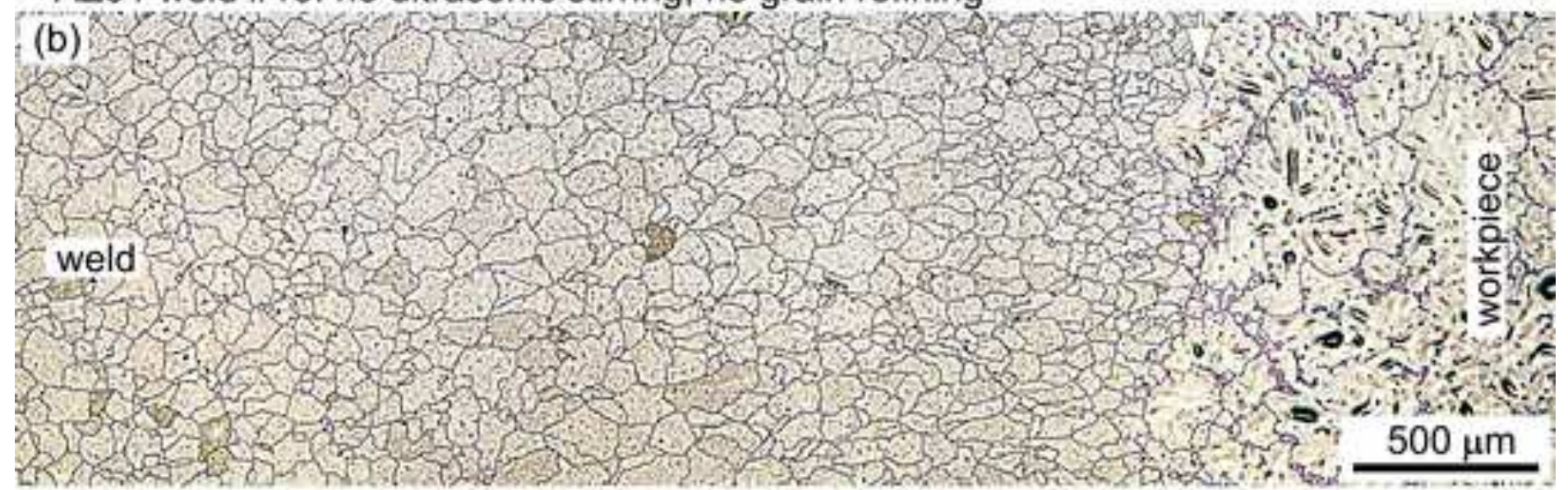

AZ91 weld \#16: ultrasonic probe $3 \mathrm{~mm}$ behind arc; effective grain refining

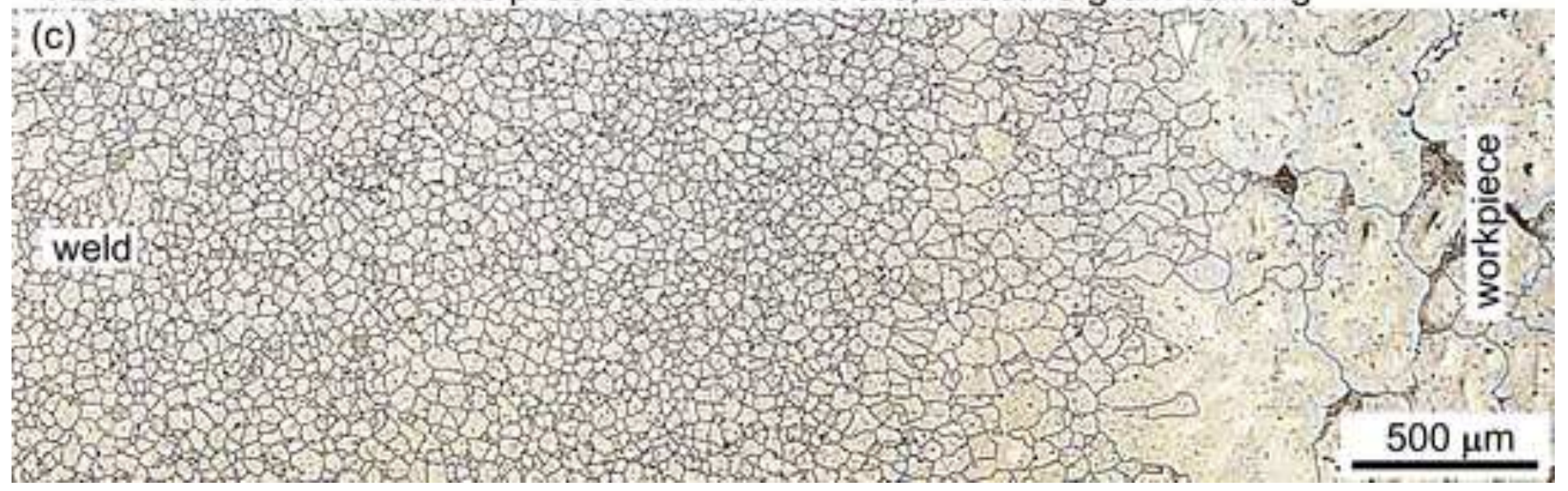




\section{Grain Refining by Ultrasonic Stirring of the Weld Pool}

\section{Graphic abstract}

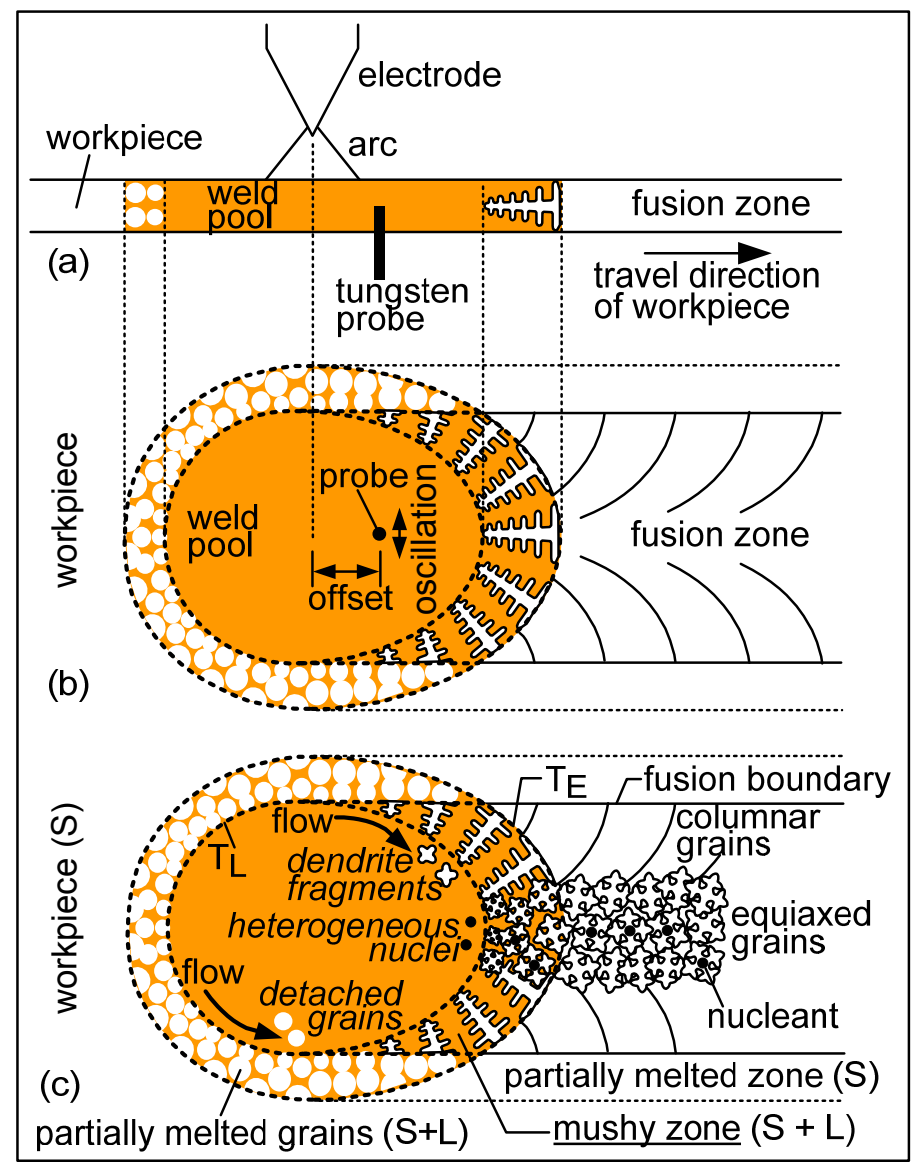

Grain refining can improve the mechanical properties and solidification-cracking resistance of the weld. Ultrasonic grain refining with a probe dipped in the weld pool at a distance behind the arc produced effective grain refining in Mg alloys AZ31 $(\sim \mathrm{Mg}-3 \mathrm{Al}-1 \mathrm{Zn})$ and AZ91( $\sim \mathrm{Mg}-9 \mathrm{Al}-$ $1 \mathrm{Zn}$ ). Grain refining was found to increase with increasing offset, oscillation amplitude, and alloying content. However, with an excessive offset the probe can be located inside the mushy zone and grain refining, though very effective,can be limited to near the weld centerline. Dendrite fragmentation was the most likely grain refining mechanism. 